Research Article

\title{
Investigation on Seismic Performance of Bidirectional Self-Centering Reinforced Concrete Frame Structures by Shaking Table Tests
}

\author{
Zhenying Wang $\mathbb{D}^{1},{ }^{1}$ Chenxi Mao, ${ }^{2}$ and Lili Xie ${ }^{1,2}$ \\ ${ }^{1}$ School of Civil Engineering, Harbin Institute of Technology, Harbin 150090, China \\ ${ }^{2}$ Key Laboratory of Earthquake Engineering and Engineering Vibration, Institute of Engineering Mechanics, \\ China Earthquake Administration, Harbin 150080, China \\ Correspondence should be addressed to Zhenying Wang; zhenyingwang@outlook.com
}

Received 16 September 2019; Revised 14 December 2019; Accepted 21 December 2019; Published 29 January 2020

Academic Editor: Nicola Caterino

Copyright (c) 2020 Zhenying Wang et al. This is an open access article distributed under the Creative Commons Attribution License, which permits unrestricted use, distribution, and reproduction in any medium, provided the original work is properly cited.

\begin{abstract}
This paper presents an experimental study on the seismic performance of a bidirectional self-centering reinforced concrete (RC) frame structure. In the structure, the column-base joints, which were installed with external mild steel (MS) dampers, could uplift freely and the beam-column joints could open effectively under earthquake excitations. Angle steels and MS dampers were installed at the beam-column joints in the structural $X$ and $Y$ directions, respectively. During the gap opening of the joints, unbonded posttensioned (PT) steel wires, which passed through the plastic ducts inserted in the RC beams and columns, provided the structure with the ability to return to pre-earthquake positions, and the yielding MS dampers and angle steels dissipated the seismic energy. A 1/2-scale two-story model structure was designed and constructed. Shaking table tests were performed on the structure under four different types of earthquake excitations with increasing seismic hazard levels. The test results indicated that the self-centering RC frames installed in both the directions showed satisfactory seismic performance, with only slight damage to the main structure after extreme earthquakes. The natural frequencies of the self-centering frames installed in both the directions degraded progressively, mainly because of the prestress loss of the PT steel wires and the yielding of the MS dampers. The structure showed desirable self-centering ability with very small residual deformation under ground motions of all hazard levels. The structural deformation was mainly concentrated at the column-base and beam-column joints, and hence, damage to the concrete beams and columns was considerably alleviated. In addition, the residual gap opening of the joints was minimal.
\end{abstract}

\section{Introduction}

Recent earthquake events have caused severe damage to conventional concrete structures and induced massive economic losses, and people are finding it increasingly difficult to cope with such losses. Under such circumstances, self-centering structural systems are expected to mitigate structural damage and reduce economic losses resulting from earthquakes.

The concept of self-centering reinforced concrete (RC) frames was developed as part of the Precast Seismic Structural Systems research program $[1,2]$. In a structure with such frames, precast beams and columns are connected by unbonded posttensioned (PT) tendons, which provide a restoring force to the entire structure. During an earthquake, the seismic energy propagating to the structure is dissipated by additional energy dissipation (ED) devices. The gap opening mechanism between structural members is expected to produce a typical flag-shaped hysteretic behavior in the structure (Figure 1). The structural deformation is mainly concentrated at the beam-column and column-base joints, which exhibit an open-close behavior of the gap under earthquake excitation. The entire structure is expected to return to its pre-earthquake position with minimal residual deformation because of the clamping action of the PT tendons. 


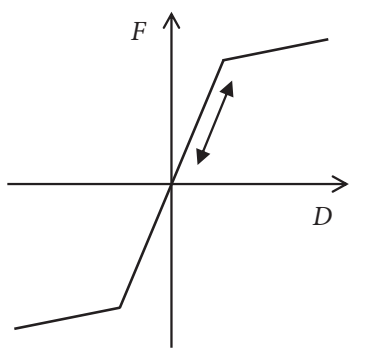

(a)

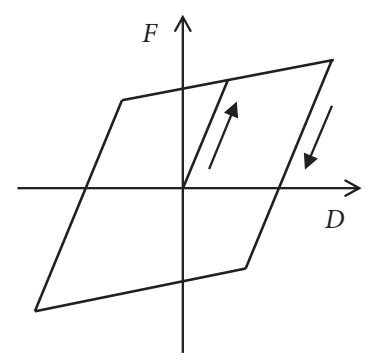

(b)

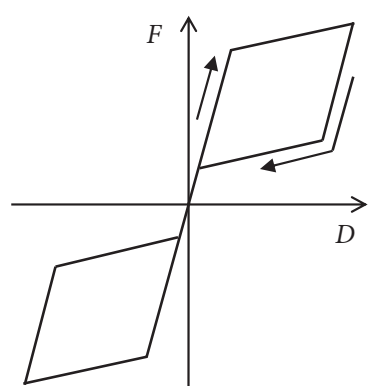

(c)

FIgURE 1: Typical flag-shaped hysteretic behavior of the structure. (a) Response generated by PT tendons. (b) Response generated by ED devices. (c) Combined behavior of PT tendons and ED devices.

Extensive investigations have validated that PT RC beam-column joints [3-10] and column (pier)-foundation joints [11-14] have excellent self-centering ability with little residual deformation under quasistatic cyclic loading. Many ED devices have been developed, ranging from internal mild steel (MS) rebars $[3-5,8]$ to external dampers mounted at joints, which are easy to replace after failure, such as MS dampers $[7,9,12,13]$, friction dampers $[6,10]$, and angle steels $[15,16]$.

However, after many years of research, knowledge regarding the actual seismic performance of the overall structural system equipped with self-centering $\mathrm{RC}$ frames is still quite limited, which is one of the primary reasons that have prevented its wide application. Until now, self-centering RC frames have been used only in a small number of engineering projects, which are located in the United States [17] and New Zealand [18, 19]. Thus, more attention has been paid recently to the seismic performance of the overall structural system. Shaking table tests have been performed on a $1 / 2$-scale two-story unidirectional self-centering RC frame [15]. Cui et al. [16] performed shaking table tests on a $1 / 2.5$-scale three-story self-centering RC frame structure with sliding floor slabs. These test structures with unique connection systems showed satisfactory seismic performance and self-centering capacity under typical severe ground motions.

It is noteworthy that only few studies have investigated the seismic performance of bidirectional self-centering RC frames, especially the performance of these frames with external dampers installed at the joints. In this study, a 1/2scale two-story model of self-centering frames installed in both the $X$ and $Y$ directions was designed and constructed. In this model, external MS dampers were installed at the column-base and beam-column joints of the $Y$-direction frame, whereas angle steels were mounted at the beamcolumn joints of the $X$-direction frame. PT steel wires, which passed through the plastic ducts inserted in the RC beams and columns, provided the self-centering ability to the structure, and the yielding MS dampers and angle steels dissipated the seismic energy. The actual seismic performance of the structure was investigated by performing shaking table tests under four different types of earthquake excitations with increasing seismic hazard levels. The results of this study are expected to fill the gaps in the literature and contribute to a deeper understanding of the seismic behavior of self-centering RC frame structures.

\section{Experimental Setup and Program}

2.1. Overview of the Test Structure. To investigate the seismic behavior of bidirectional self-centering RC frames, a 1/2scale frame was constructed and tested on the shaking table at the Key Laboratory of Earthquake Engineering and Engineering Vibration at the Institute of Engineering $\mathrm{Me}$ chanics, China Earthquake Administration.

The prototype structure was a two-story RC frame, which was designed following the displacement-based design procedure [20-22]. The design interstory drift was assumed as $2.0 \%$ under large earthquakes, which was the drift limit of RC frames per the Chinese seismic design code [23]. The building was assumed to be located in an area with a seismic fortification intensity of 8.0 (with design peak ground accelerations (PGAs) of $0.1,0.2$, and $0.4 \mathrm{~g}$, which represented seismic hazards of $63 \%, 10 \%$, and $2 \%$ probability of exceedance in 50 years, respectively). The seismic design site category was Site Class II in China. The plan dimension of the prototype building was $5.44 \times 5.44 \mathrm{~m}$. There was one bay in both the $X$ and $Y$ directions. The total height of the building was $6.60 \mathrm{~m}$, with each story having a height of $3.30 \mathrm{~m}$. The dead load on each floor was assumed as $6.91 \mathrm{kPa}$ (including the floor slab self-weight), and the live load was $2.0 \mathrm{kPa}$.

Taking the physical limitations (e.g., dimension and loading capacity) of the shaking table into account, the prototype building was scaled to a $1 / 2$-scale test structure. The primary similitude scale factors of the test structure were determined under the similitude law [24], as summarized in Table 1. Figure 2(a) shows the plan view of the test building. The floor slab was supported only on $X$-direction beams. There were gaps of $50 \mathrm{~mm}$ between the floor slab and $Y$ direction beams at each story, and these gaps were infilled with Styrofoam before the test. The reserved gaps released the constraints of the floor slab to the beam-column joints of both the $X$ - and $Y$-direction frames; that is, the gaps guaranteed that the joints would open effectively under earthquake excitations. The component and joint numbers are also shown in the figure, with " $\mathrm{C}$," "B," and "J" representing the columns, beams, and joints, respectively. The 
TABle 1: Similitude scale factors.

\begin{tabular}{lcc}
\hline Parameter & Relationship & Model/prototype \\
\hline Length & $S_{l}$ & 0.500 \\
Strain & $S_{\varepsilon}$ & 1.000 \\
Young's modulus & $S_{E}$ & 1.000 \\
Stress & $S_{\sigma}=S_{E}$ & 1.000 \\
Density & $S_{\rho}=S_{E} /\left(S_{a} S_{l}\right)$ & 1.538 \\
Mass & $S_{m}=S_{\rho} S_{l}^{3}$ & 0.192 \\
Force & $S_{F}=S_{\sigma} S_{l}^{2}$ & 0.250 \\
Moment & $S_{M}=S_{\sigma} S_{l}^{3}$ & 0.125 \\
Rigidity & $S_{k}=S_{\sigma} S_{l}$ & 0.500 \\
Acceleration & $S_{a}$ & 1.300 \\
Time & $S_{t}=\sqrt{S_{l} / S_{a}}$ & 0.620 \\
Frequency & $S_{f}=1 / S_{t}$ & 1.612 \\
\hline
\end{tabular}

elevation views of the $X$ - and $Y$-direction frames are illustrated in Figures 2(b) and 2(c), respectively. The PT steel wires passed in a straight line through the plastic ducts inserted in the columns and $X$-direction beams, whereas the $\mathrm{PT}$ wires in the $Y$-direction beams had an oblique symmetrical configuration. The PT wires in the columns were anchored at the base at one end and at the column top at the other end. The PT wires in the beams were anchored at the column end stubs with a dimension of $300 \times 465 \mathrm{~mm}$ at each beam-column joint. The MS dampers were installed at the column-base joints and $Y$-direction beam-column joints, whereas the angle steels were mounted at the $X$-direction beam-column joints. The construction of the self-centering joints is detailed in Section 2.2. The cross-sectional dimensions of the columns and beams were $350 \times 350$ and $200 \times 300 \mathrm{~mm}$, respectively. The section reinforcement of the concrete beams, columns, and slabs is shown in Figure 3. The floor slab was only cast together with the $X$-direction beams of each story. The angle steel was mounted at each beamcolumn joint of $X$-direction frames (Figure $4(\mathrm{~b})$ ). The angle steel has relatively large in-plane stiffness along the $Y$ direction of the structure. Thus, the lateral loads in the $X$ and $Y$ directions could be transferred from the floors into the frames by $X$-direction beams and angle steels, respectively. The total weight of the test structure was 26.96 ton, which included the base weight ( 6.12 ton), the self-weight of the test structure (8.08 ton for each story), and the added mass (2.34 ton on each floor slab), respectively. The added mass was attached on each floor slab in the form of steel blocks $(20 \mathrm{~kg}$ for each block), as shown in Figure 4(b).

2.2. Connection Details of the Test Structure. The bidirectional self-centering $\mathrm{RC}$ frame used for the test included the following types of connections: (a) the beam-column joints of the $X$-direction frame, (b) the beam-column joints of the $Y$-direction frame, and (c) the column-base joints. The connections were designed based on the design moment, which was determined by the connection moment of the prototype structure multiplied by the moment similitude scale factor $\left(S_{M}=0.125\right)$. Then, the connection design moment was distributed to the PT steel wires and ED devices, as shown by equation (1). The initial posttensioning stress applied was closely related to other design parameters of PT steel wires, that is, the location of the PT steel wires and the total section area of the PT steel wires. Although the same connection moment demand $\left(M_{p t}\right)$ to be achieved by the PT steel wires, the various posttensioning stress was adopted due to different arrangements of the PT steel wires in $X$ - and $Y$-direction beams. Similarly, the main design parameters of MS dampers include the location of the MS dampers mounted, the diameter of the fuse bar, and the length of the fuse bar. Different parameters of MS dampers were used in beam-column and column-base joints to meet different moment demands $\left(M_{s}\right)$ to be provided by the dampers.

Figure 5(a) shows the configuration of the beam-column joints of $X$-direction frames. The beams were supported on concrete corbels. Steel plates with thicknesses of $10 \mathrm{~mm}$ were embedded at the beam ends and column surfaces to protect the concrete from severe damage when the joint gaps opened. Two PT steel wires (diameter: $7 \mathrm{~mm}$ ) horizontally passed through two plastic ducts inserted in the beams and anchored at the column end stubs. An initial posttensioning stress of $650 \mathrm{MPa}\left(0.41 f_{p t k}\right)$ was designed to be applied, resulting in an initial posttensioning force per steel wire of $25.01 \mathrm{kN}$. Angle steels with a characteristic yielding strength of $235 \mathrm{MPa}$ served as ED devices when the joints opened. The details of the angle steels are shown in Figure 6. Bolts were used to fix the angle steels and embedded steel plates. The beam-column joints were designed such that they would begin to open under moderate earthquakes. The joints had the ability to recenter to their pre-earthquake positions because of the clamping force of the PT steel wires.

Figure 5(b) illustrates the configuration of the beamcolumn joints of $Y$-direction frames. This configuration was designed by referring to a previous study [9]. The beam ends were armored by an assembly of steel plates that were welded together. The beams were supported on steel corbels through a round steel rod with a diameter of $50 \mathrm{~mm}$. The round steel rod acted as a rotation point between the beam end and column. A T-shaped steel plate was installed on the top of the round steel rod to prevent the beam from uplift and torsion. Bolts were used to fix the assembly of steel plates at the beam ends, the steel corbels, and the T-shaped steel plates at the column side. Four PT steel wires (diameter: $7 \mathrm{~mm}$ ) symmetrically passed through four oblique plastic ducts inserted in the beams and anchored at the stubs at both sides. An initial posttensioning stress of $857 \mathrm{MPa}\left(0.55 f_{p t k}\right)$ was designed to be applied, resulting in an initial posttensioning force per steel wire of $32.98 \mathrm{kN}$. MS dampers were fabricated and installed at both sides of the joints to dissipate the seismic energy. The joints were designed to return to their original positions through the action of the stretched PT steel wires after an earthquake.

The construction details of the MS dampers are shown in Figure 7(a). The damper was designed by referring to a previous study [25] and fabricated using a Q235B round MS bar with a characteristic strength of $235 \mathrm{MPa}$. The bar diameter was reduced over a predetermined length so that it could serve as the fuse bar to dissipate energy from the region where plastic deformation was concentrated. The diameter of the fuse bar was $10 \mathrm{~mm}$, and its length was 

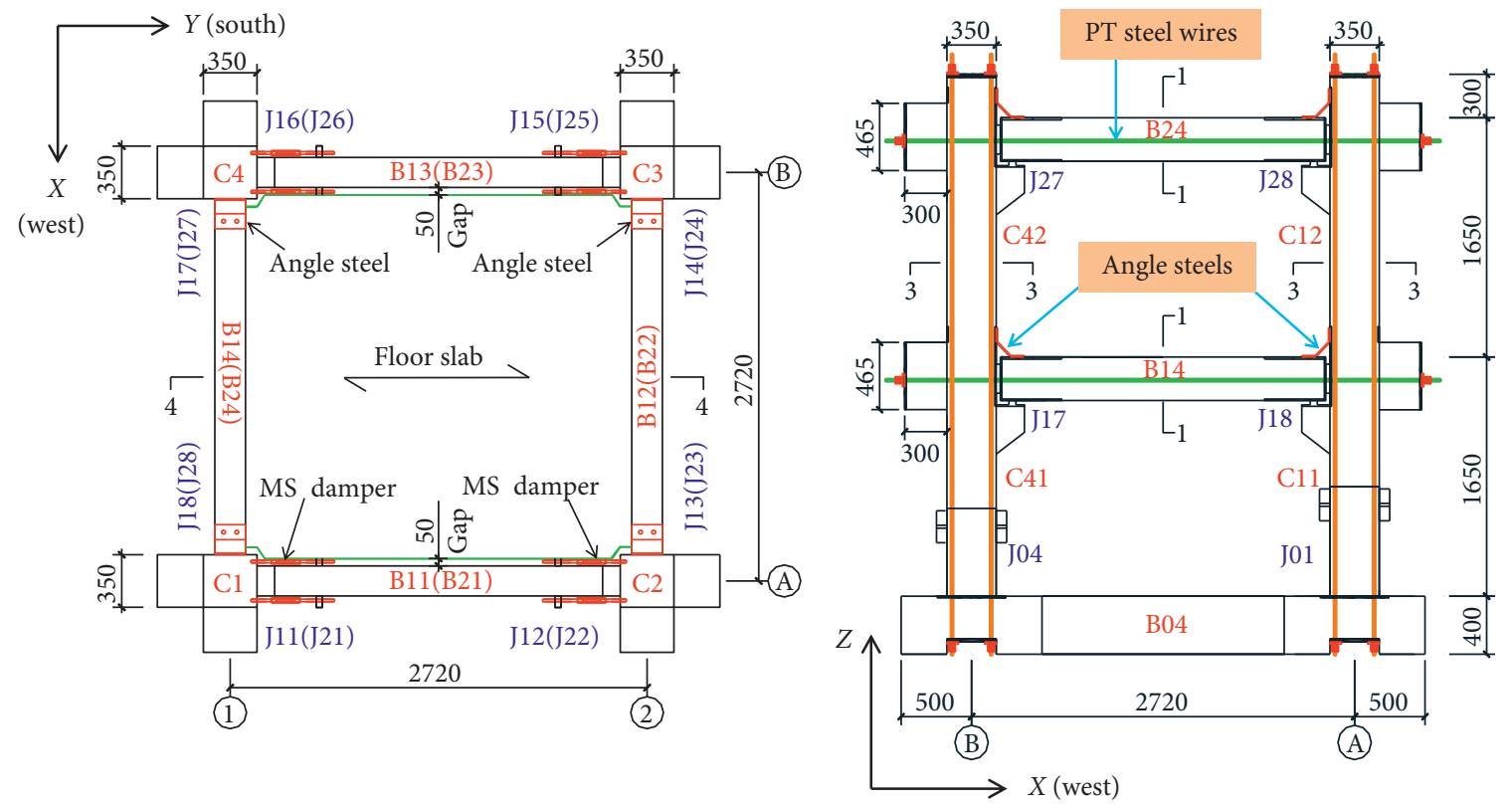

(a)

(b)

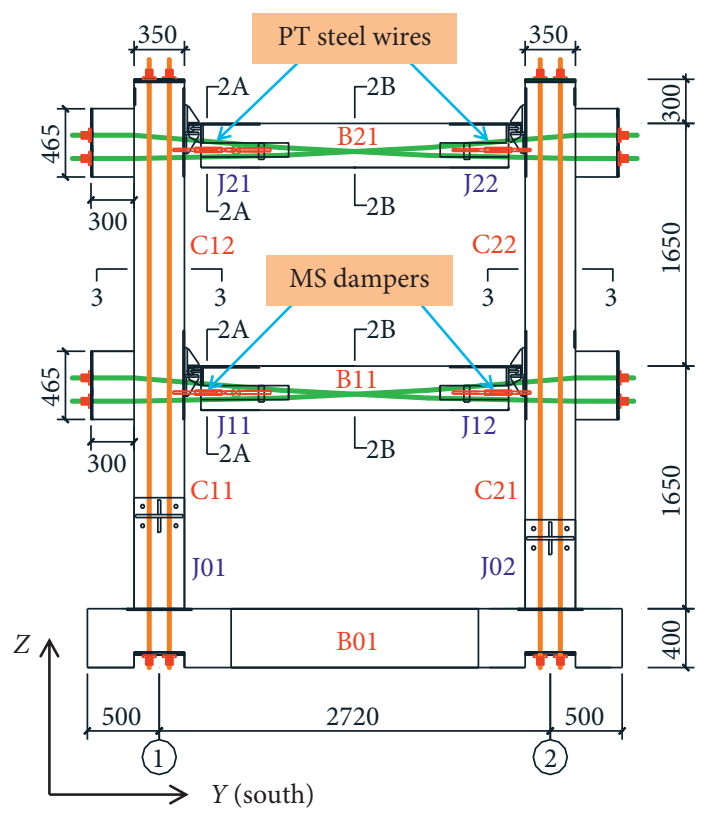

(c)

Figure 2: Configuration of the test structure (dimensions in millimeters). (a) Plan view. (b) Elevation view of the $X$-direction frame. (c) Elevation view of the $Y$-direction frame.

$100 \mathrm{~mm}$. A steel tube with an outside diameter of $33.7 \mathrm{~mm}$ and a wall thickness of $3.2 \mathrm{~mm}$ was placed over the fuse bar and temporarily fixed in place to serve as an antibuckling restraint. Silicone grease was smeared on the steel bar to ensure that the bar could deform freely under axial tension and compression. Steel gaskets with thicknesses of $5 \mathrm{~mm}$ were attached to both sides of the steel tube. Epoxy was then injected into the space between the bar and steel tube, as shown in Figure 7(b). The threaded ends of the MS dampers were fixed to the steel components, which were embedded in the beams and columns.
Figure 5(c) shows the configuration of the column-base joints. The column bottom was armored with steel boots, which were made of steel plates with thicknesses of $10 \mathrm{~mm}$. In addition, steel plates with thicknesses of $10 \mathrm{~mm}$ were embedded on the top of the base. Hence, local concrete crushing could be avoided when the column rocked. Four PT steel wires (diameter: $7 \mathrm{~mm}$ ) vertically passed through four plastic ducts inserted in the base and column. The ends of the PT steel wires were anchored on the steel plates in the base and column top. An initial posttensioning stress of $800 \mathrm{MPa}\left(0.51 f_{p t k}\right)$ was designed to be applied, resulting in 


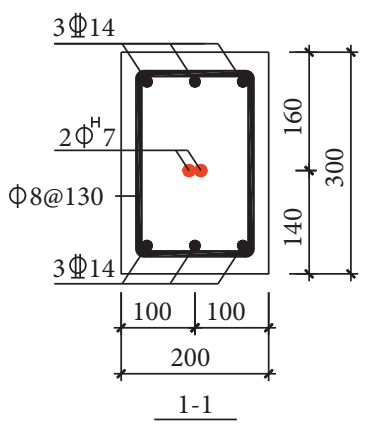

(a)

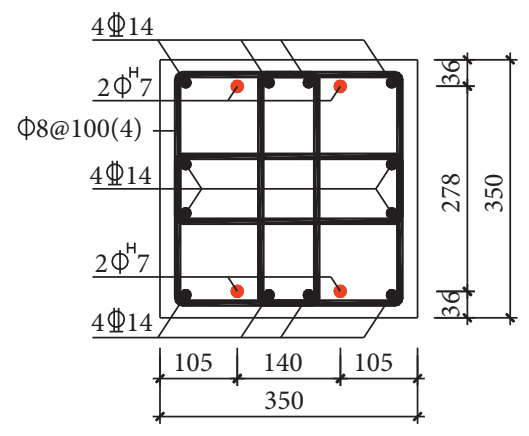

(c)
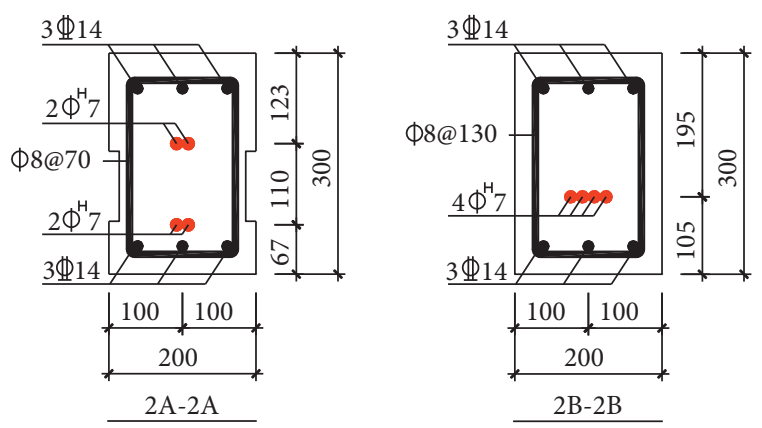

(b)

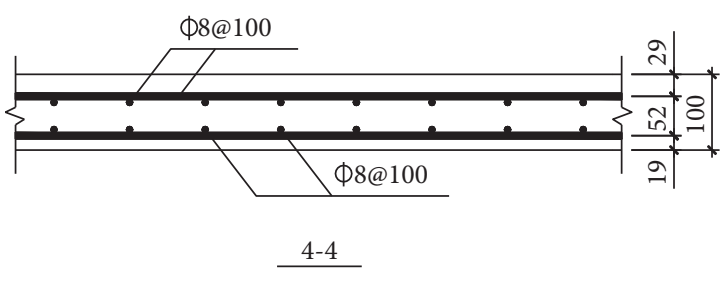

(d)

FIGURE 3: Reinforcement details of the test structure (dimensions in millimeters). (a) Beam section of the $X$-direction frame. (b) Beam section of the $Y$-direction frame. (c) Column section. (d) Slab section.
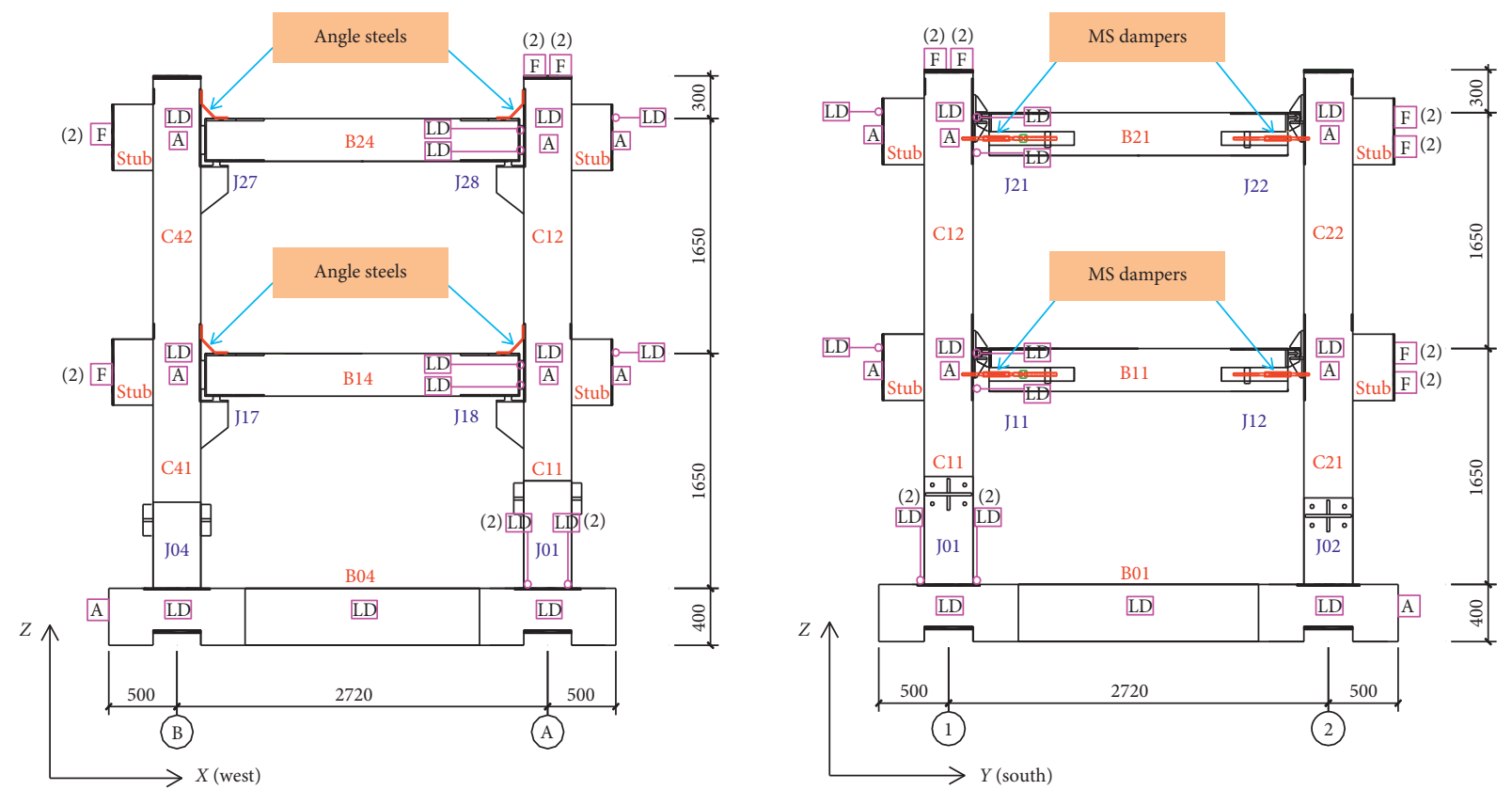

(a)

FIgURE 4: Continued. 

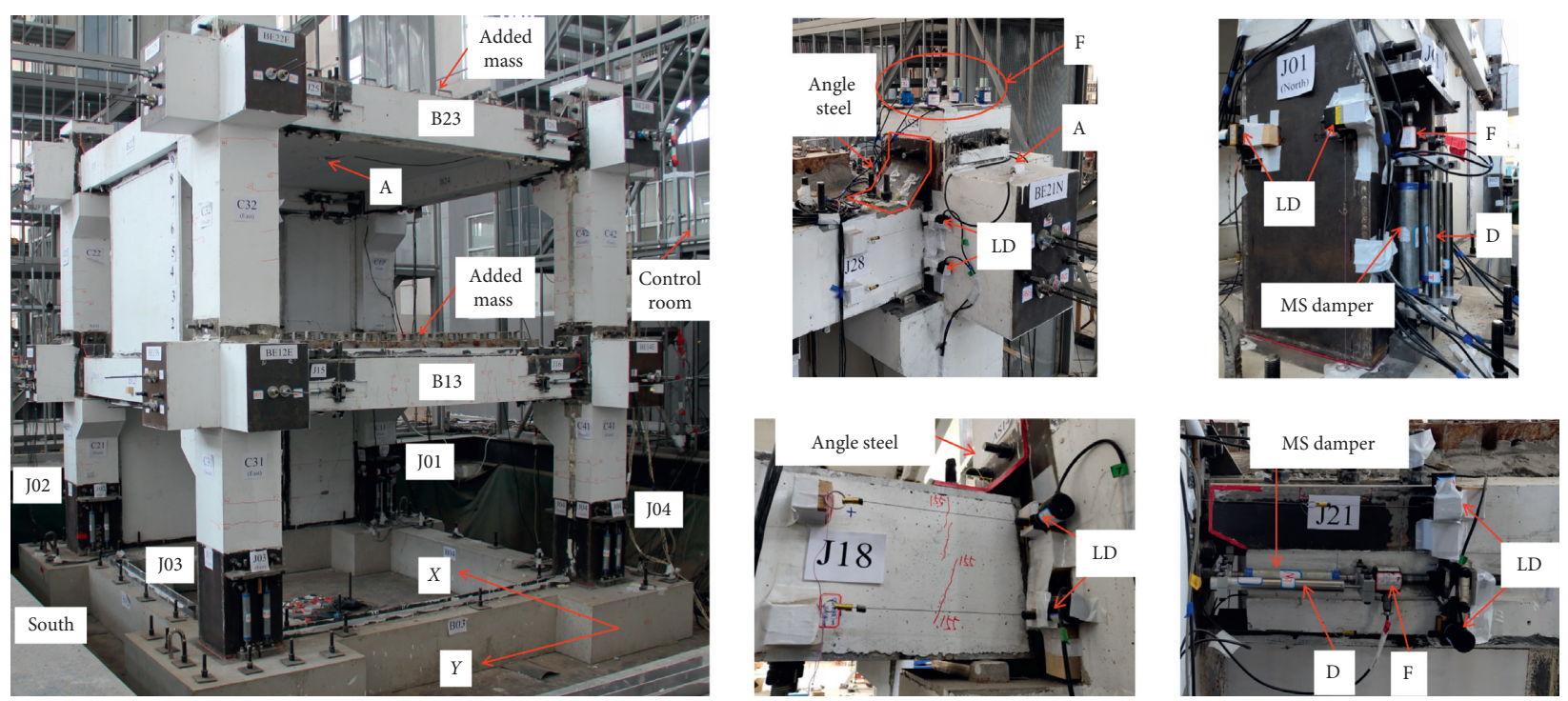

(b)

FIGURE 4: Instrument layout of the test structure. (a) Schematic of instrument arrangement. (b) Typical onsite instrument arrangement.

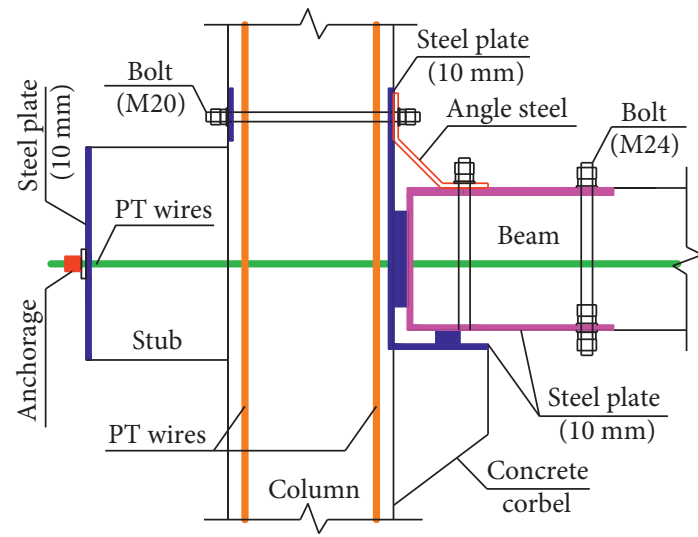

(a)

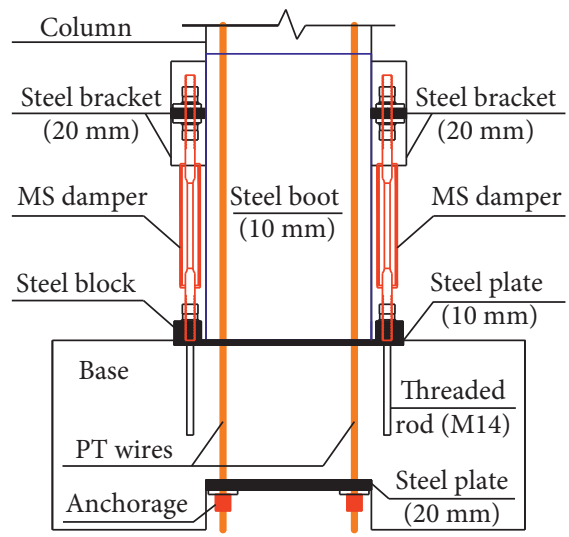

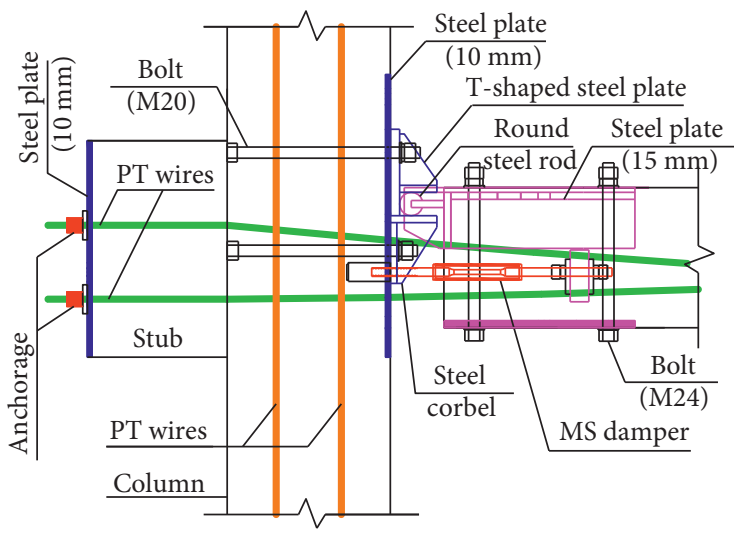

(b)

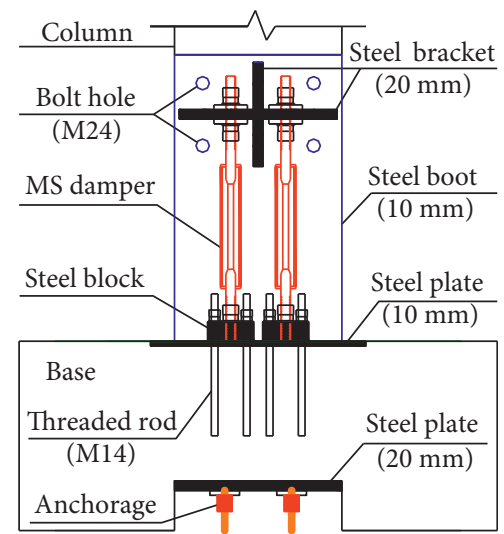

(c)

Figure 5: Connection details of the test structure. (a) Beam-column joints of $X$-direction frames. (b) Beam-column joints of $Y$-direction frames. (c) Column-base joints. 


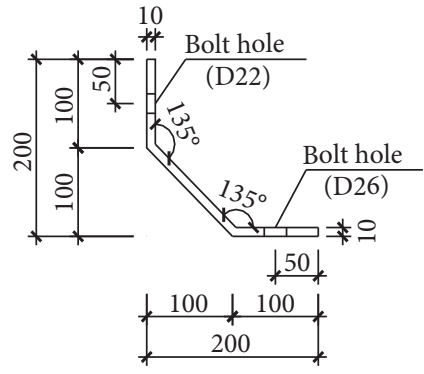

(a)

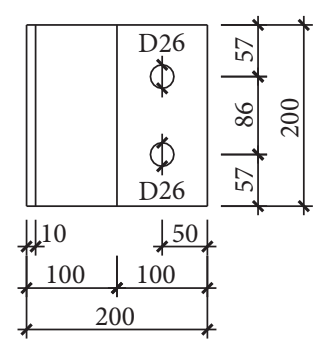

(b)

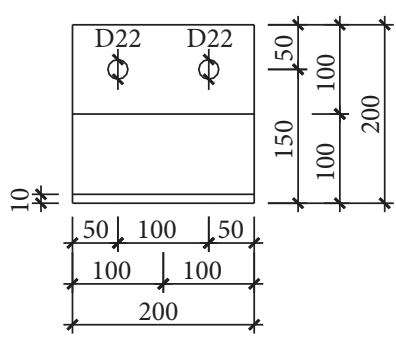

(c)

FIgURE 6: Details of angle steels (dimensions in millimeters). (a) Elevation view. (b) Plan view. (c) Front view.

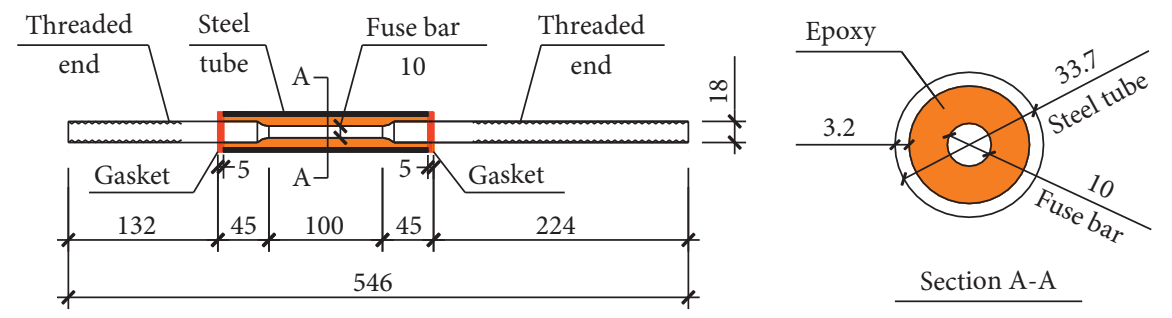

(a)

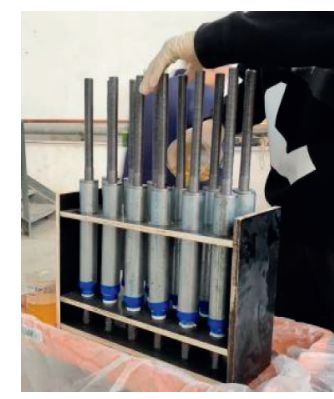

(b)

FIGURE 7: Details of MS dampers at beam-column joints (dimensions in millimeters). (a) Construction of MS dampers. (b) Epoxy infilling process.

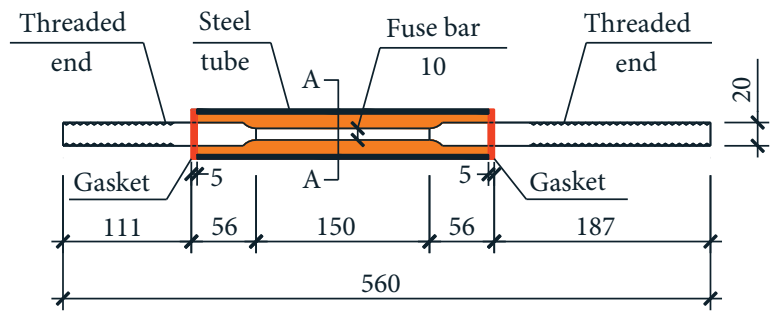

(a)

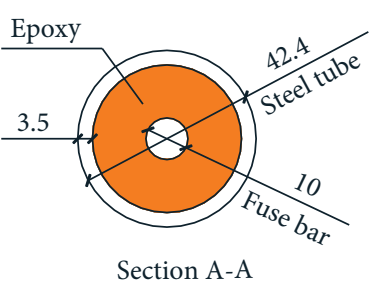

Section A-A

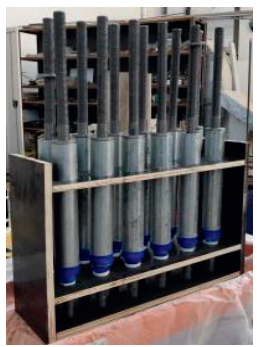

(b)

Figure 8: Details of MS dampers at column-base joints (dimensions in millimeters). (a) Construction of MS dampers. (b) Completed epoxy infilling process.

an initial posttensioning force per steel wire of $30.78 \mathrm{kN}$. Four MS dampers were attached to the joints to serve as energy dissipaters. Under moderate earthquakes, the joints were expected to open. The recentering ability of the joints was provided by the stretched PT steel wires and the column axial force induced by the self-weight of the structure.

The construction details of the MS dampers are shown in Figure 8 . The fabrication process was the same as that for the dampers at the beam-column joints. The diameter of the fuse bar was $10 \mathrm{~mm}$, and its length was $150 \mathrm{~mm}$. The outside diameter and wall thickness of the steel tube were 42.4 and $3.5 \mathrm{~mm}$, respectively. The threaded ends of the MS dampers
TABLE 2: Acceleration amplitudes of main excitation.

\begin{tabular}{lccccccc}
\hline \multirow{2}{*}{ PGA (g) } & Level & Level & Level & Level & Level & Level & Level \\
& 1 & 2 & 3 & 4 & 5 & 6 & 7 \\
\hline Prototype & 0.10 & 0.20 & 0.40 & 0.60 & 0.80 & 1.00 & 1.20 \\
Model & 0.13 & 0.26 & 0.52 & 0.78 & 1.04 & 1.30 & 1.56 \\
\hline
\end{tabular}

Levels 1,2 , and 3 represent small, moderate, and large earthquakes, respectively, prescribed in the Chinese seismic design code [23].

were connected to the steel block on the top of the foundation at one side and the steel bracket welded to the steel boots at the other side. The steel block was bolted to the foundation using threaded rods $(14 \mathrm{~mm}, 800 \mathrm{MPa})$ with an embedment depth of $200 \mathrm{~mm}$. 


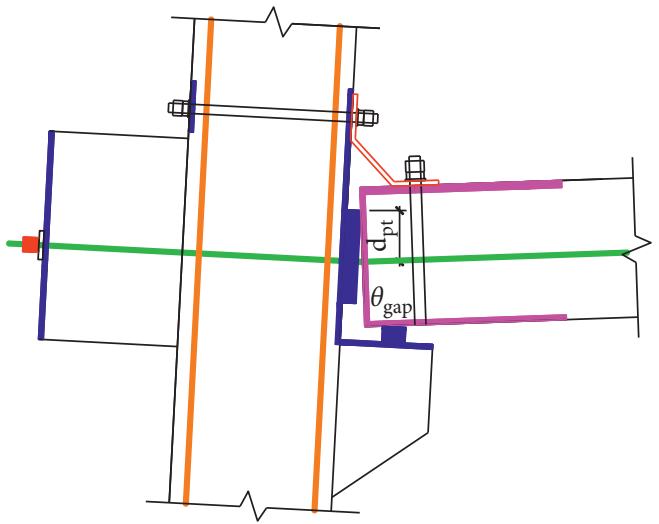

(a)

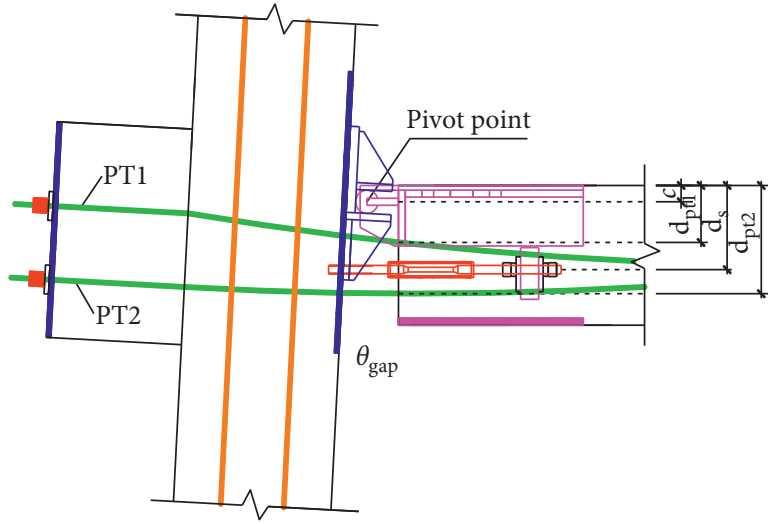

(b)

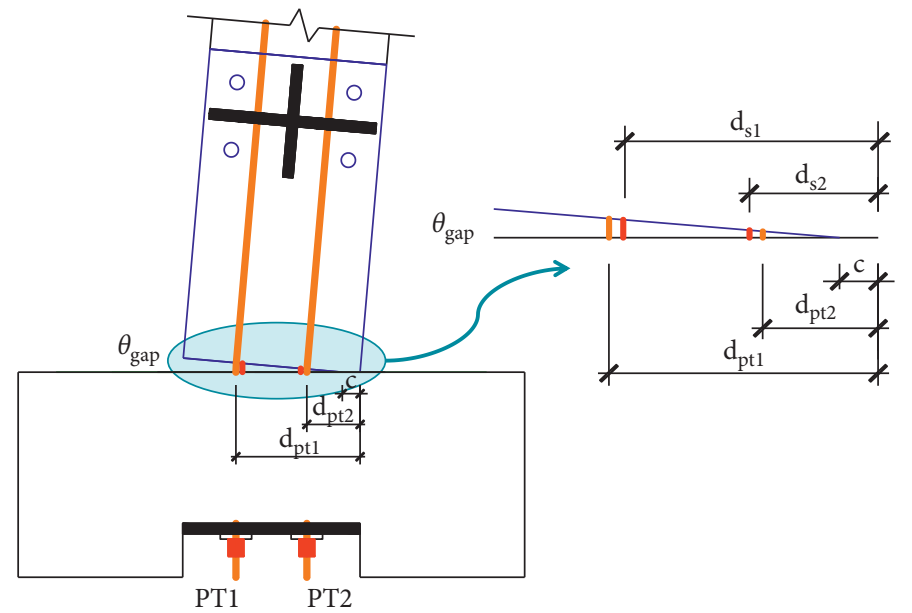

(c)

FIgURE 9: Schematic of gap opening state of the joints. (a) Beam-column joints of the $X$-direction frame. (b) Beam-column joints of the $Y$ direction frame. (c) Column-base joints.

The following design principles [26] were employed to ensure the self-centering ability of the joints in the design phase:

(1) The ratio of moment contribution $\lambda$ (i.e., selfcentering ratio) of both the beam-column and column-base joints should satisfy the following relationship:

$$
\begin{aligned}
\lambda=\frac{M_{p t}+M_{N}}{M_{s}} & \geq \alpha_{0}, \\
\alpha_{0} & \geq 1.15,
\end{aligned}
$$

where $M_{p t}, M_{N}$, and $M_{s}$ are the moments provided by the PT steel wires, column axial force caused by the self-weight, and ED devices, respectively, and $\alpha_{0}$ is the overstrength factor for the ED devices and should be larger than 1.15. In this study, the selfcentering ratio $\lambda=1.25$ was adopted.

(2) The PT steel wires should remain elastic under large earthquakes (level 3, as shown in Table 2). The initial prestress was determined as follows:

$$
\begin{aligned}
f_{p t, \text { initial }} & \leq 0.9 f_{p t y}-E_{p t} \Delta \varepsilon_{p t}, \\
\Delta \varepsilon_{p t} & =\frac{\Delta_{p t}^{\text {total }}}{L_{p t}},
\end{aligned}
$$

where $f_{p t \text {,initial }}, f_{p t y}$, and $E_{p t}$ are the initial prestress after losses, yield strength, and elastic modulus of the PT steel wires, respectively, and $\Delta \varepsilon_{p t}$ is the strain increment of the PT steel wires resulting from the gap opening; $L_{p t}$ is the total unbonded length of the PT steel wires; $\Delta_{p t}^{\text {total }}$ is the total elongation of the PT steel wires induced by gap openings under the design interstory drift. The following assumptions were adopted to calculate $\Delta_{p t}^{\text {total }}$ : the design interstory drift was assumed as $2.0 \%$ under large earthquakes, which was the drift limit of RC frames per the Chinese seismic design code [23]. The interface gap rotation of the column-base and beam-column joints was approximately equal to the interstory drift.

Figure 9(a) shows the deformation schematic of the $X$ direction beam-column joints. The total deformation of the unbonded PT steel wires $\left(\Delta_{p t}^{\text {total }}\right)$ can be calculated as 


$$
\begin{aligned}
\Delta_{p t}^{\text {total }} & =n \Delta_{p t}, \\
\Delta_{p t} & =\theta_{\text {gap }} d_{p t},
\end{aligned}
$$

where $n$ is the total number of joint openings that the continuous PT steel wires pass through (herein, $n=2$ for the PT steel wires in $X$-direction beams), $\Delta_{p t}$ is the elongation of the PT steel wires due to the individual opening gap, $\theta_{\text {gap }}$ is the joint gap rotation under the design interstory drift, and $d_{p t}$ is the distance from the PT steel wires to the edge of the compression area.

Figure 9(b) shows the deformation schematic of the $Y$ direction beam-column joints. It is noted that the unbonded PT steel wires are antisymmetric, and the neutral axis position $(c)$ is fixed assuming that the round steel rod can act as a pivot point. The gap of the right joint would be closed when the gap opening of the left joint occurred. Therefore, the total deformation of the unbonded PT steel wires $\left(\Delta_{p t}^{\text {total }}\right)$ can be calculated as

$$
\Delta_{p t}^{\mathrm{total}}=\Delta_{p t}^{\mathrm{left}}+\Delta_{p t}^{\mathrm{right}},
$$

where $\Delta_{p t}^{\text {left }}$ and $\Delta_{p t}^{\text {right }}$ are the deformation of the PT steel wires induced by the left and right gap openings, respectively.

Specifically, for the PT steel wires 1 and 2,

$$
\begin{aligned}
\Delta_{p t 1}^{\mathrm{total}} & =\Delta_{p t 1}^{\mathrm{left}}+\Delta_{p t 1}^{\mathrm{right}}, \\
\Delta_{p t 2}^{\mathrm{total}} & =\Delta_{p t 2}^{\mathrm{left}}+\Delta_{p t 2}^{\mathrm{right}}, \\
\Delta_{p t 1} & =\theta_{\text {gap }}\left(d_{p t 1}-c\right), \\
\Delta_{p t 2} & =\theta_{\text {gap }}\left(d_{p t 2}-c\right),
\end{aligned}
$$

where $\theta_{\text {gap }}$ is the joint gap rotation under the design interstory drift, $d_{p t 1}$ and $d_{p t 2}$ are the height of the PT steel wires 1 and 2, respectively, and $c$ is the height of the pivot point.

Figure 9(c) shows the deformation schematic of the column-base joint. The total deformation of the unbonded posttensioned tendons $\left(\Delta_{p t}^{\text {total }}\right)$ can be calculated as

$$
\Delta_{p t}^{\text {total }}=n \Delta_{p t}
$$

Specifically, for the PT steel wires 1 and 2,

$$
\begin{aligned}
& \Delta_{p t 1}=\theta_{\text {gap }}\left(d_{p t 1}-c\right), \\
& \Delta_{p t 2}=\theta_{\text {gap }}\left(d_{p t 2}-c\right),
\end{aligned}
$$

where $n$ is the total number of joint openings that the continuous PT steel wires pass through (herein, $n=1$ for the PT steel wires in columns), $\Delta_{p t 1}$ and $\Delta_{p t 2}$ are the elongation of the PT steel wires due to individual gap opening, $\theta_{\text {gap }}$ is the joint gap rotation under the design interstory drift, $d_{p t 1}$ and $d_{p t 2}$ are the distance from the PT steel wires to the assumed neutral axis position, and $c$ is the assumed neutral axis depth of the section ( $c=0.1 h_{c}$, where $h_{c}$ is the column depth).

2.3. Material Properties. The materials of the test structure were selected according to the mechanical property similarities between the test model and prototype. Fine aggregate concrete with a characteristic strength of $35 \mathrm{MPa}$ was adopted for the test structure. The concrete of the entire structure was cast in three parts. The measured parameters of the concrete at each location are listed in Table 3.

A grade HRB400 rebar with a diameter of $14 \mathrm{~mm}$ was adopted as the longitudinal reinforcement for the RC beams and columns. Grade HRB400 reinforcement with a diameter of $8 \mathrm{~mm}$ was utilized as the stirrups for the beams and columns and the longitudinal rebar in the floor slabs. Grade HRB400 rebars with diameters of 10 and $22 \mathrm{~mm}$ were used as the stirrups and longitudinal reinforcement in the base, respectively. Unbonded PT steel wires of grade $1570 \mathrm{MPa}$ with a diameter of $7 \mathrm{~mm}$ passed through the plastic ducts inserted in the beams and columns. The parameters of the reinforcement and PT steel wires are listed in Tables 4 and 5, respectively.

2.4. Data Acquisition. The structural responses were monitored during the entire test, including the horizontal displacements and accelerations of each floor, gap opening displacement of the joints, axial forces of PT steel wires, and deformation of MS dampers. The instrument arrangement of the structure is summarized in Table 6. Figures 4(a) and 4(b) show the schematic of the instrument arrangement and the typical onsite arrangement, respectively. For clarity, the PT steel wires in the beams and columns were not shown in Figure 4(a).

2.5. Ground Motions and Test Program. In this study, four strong ground motions were selected as the input excitations to investigate the seismic performance of the self-centering frame structure, as summarized in Table 7 . The ground motion records except for the Wenchuan earthquake records were selected from the PEER NGA-West 2 database [27]. The ground motions were categorized according to the soil condition [28] and the distance from the fault rupture [29]. Categories II, III, and IV represent the soil conditions of Type II (medium-hard soil), Type III (medium-soft soil), and Type IV (soft soil) in China, respectively. FF and NF refer to far-field and near-field records.

To account for modal elongation and higher modes of the structure, for each ground motion, the mean acceleration spectrum of two record components should be near the target spectrum within the period range from $0.2 T_{1}$ to $1.5 T_{1}$, where $T_{1}$ was the fundamental period of the prototype structure. The procedure was consistent with that outlined in ASCE/SEI 7-10 [30]. The target acceleration spectrum was determined according to the Chinese code for the seismic design of buildings [23]. As an example, Figure 10 shows the original time-history curves and scaled spectral acceleration curves for the San Fernando earthquake records.

Two-way seismic waves were applied to the test structure. The PGA ratio of the main excitation (i.e., the record component with the larger PGA) to the secondary excitation was $1: 0.85$ [23]. The main excitation was applied first along the structural $X$ direction and then along the structural $Y$ direction. The time scale factor $S_{t}$ and acceleration scale 
TABLE 3: Measured parameters of concrete.

\begin{tabular}{lccc}
\hline Location & Structural members & Compressive strength $f_{c u, k}(\mathrm{MPa})$ & Young's modulus $E_{c}(\mathrm{MPa})$ \\
\hline Second story & Beams, columns, and floor slab & 34.4 & $3.12 \times 10^{4}$ \\
First story & Beams, columns, and floor slab & 33.2 & $3.08 \times 10^{4}$ \\
Base & $\quad$ Base beams & 36.7 & $3.18 \times 10^{4}$ \\
\hline
\end{tabular}

TABLE 4: Parameters of reinforcement.

\begin{tabular}{lcccc}
\hline Diameter $(\mathrm{mm})$ & Yield strength $f_{s y}(\mathrm{MPa})$ & Tensile strength $f_{s u}(\mathrm{MPa})$ & Young's modulus $E_{s}(\mathrm{MPa})$ & Broken elongation $\varepsilon_{s f}(\%)$ \\
\hline 8 & 476.8 & 722.2 & $2.04 \times 10^{5}$ & 13.1 \\
10 & 410.0 & 511.0 & $2.00 \times 10^{5}$ & 13.3 \\
14 & 496.7 & 777.0 & $2.05 \times 10^{5}$ & 16.1 \\
22 & 456.4 & 599.4 & $2.02 \times 10^{5}$ & 15.2 \\
\hline
\end{tabular}

TABle 5: Parameters of PT steel wires.

\begin{tabular}{lccccc}
\hline $\begin{array}{l}\text { Diameter } \\
(\mathrm{mm})\end{array}$ & $\begin{array}{c}\text { Characteristic strength } f_{\text {ptk }} \\
(\mathrm{MPa})\end{array}$ & $\begin{array}{c}\text { Yield strength } f_{\text {pty }} \\
(\mathrm{MPa})\end{array}$ & $\begin{array}{c}\text { Tensile strength } f_{\text {ptu }} \\
(\mathrm{MPa})\end{array}$ & $\begin{array}{c}\text { Young's modulus } E_{p t} \\
(\mathrm{MPa})\end{array}$ & $\begin{array}{c}\text { Broken elongation } \varepsilon_{\text {ptf }} \\
(\%)\end{array}$ \\
\hline 7 & 1570 & 1631.5 & 1779.9 & $2.05 \times 10^{5}$ & 4.06 \\
\hline
\end{tabular}

TABLE 6: Summary of instrument arrangement.

\begin{tabular}{lccc}
\hline Sensor type & Measurement & Location & Number \\
\hline Displacement meter (LD) & Floor displacement & Base beams, column stubs \\
& Gap opening displacement & Column-base joints, beam-column joints & 14 \\
\hline Accelerometer (A) & Floor acceleration & Base beams, column stubs, slab bottom & 12 \\
\hline Load cell (F) & Axial forces of PT steel wires & Column top, column stubs & 16 \\
& Axial forces of MS dampers & MS dampers & 8 \\
\hline Displacement meter (D) & Deformation of MS dampers & MS dampers & 8 \\
\hline
\end{tabular}

TABLE 7: Summary of ground motion parameters.

\begin{tabular}{|c|c|c|c|c|c|c|}
\hline Earthquake name & Year & Station & Magnitude & Record components & PGA (g) & Category \\
\hline San Fernando & 1971 & Castaic-Old Ridge Route & 6.61 & $\begin{array}{l}\text { RSN57_SFERN_ORR021 } \\
\text { RSN57_SFERN_ORR291 }\end{array}$ & $\begin{array}{l}0.320 \\
0.275\end{array}$ & $\mathrm{II} / \mathrm{FF}$ \\
\hline Parkfield-02_CA & 2004 & Vineyard Canyon & 6.0 & $\begin{array}{l}\text { RSN4074_PARK2004_VINEY-90 } \\
\text { RSN4074_PARK2004_VINEY360 }\end{array}$ & $\begin{array}{l}0.188 \\
0.261 \\
\end{array}$ & $\mathrm{II} / \mathrm{NF}$ \\
\hline Wenchuan & 2008 & 051WCW (Wolong) & 8.0 & $\begin{array}{c}\text { 051WCW080512142801-EW } \\
\text { 051WCW080512142802-NS }\end{array}$ & $\begin{array}{l}0.958 \\
0.653\end{array}$ & $\mathrm{III} / \mathrm{FF}$ \\
\hline Morgan Hill & 1984 & Foster City-APEEL 1 & 6.19 & $\begin{array}{l}\text { RSN452_MORGAN_A01040 } \\
\text { RSN452_MORGAN_A01310 }\end{array}$ & $\begin{array}{l}0.043 \\
0.065\end{array}$ & $\mathrm{IV} / \mathrm{FF}$ \\
\hline
\end{tabular}

San Fernando, Parkfield-02_CA, Wenchuan, and Morgan Hill earthquakes are denoted by "SF," "PA," "WE," and "MH," respectively.

factor $S_{a}$ were used to scale the time-history curve of the ground motions. Ground motions with seven hazard levels were selected. The acceleration amplitudes are listed in Table 2, and the test program is detailed in Table 8 . White noise scanning was undertaken for each seismic hazard level to obtain the natural frequency changes of the test structure.

\section{Results and Discussion}

3.1. Experimental Observation. During the test, the structural damage condition and responses under each seismic hazard level were observed and recorded in detail.

Under earthquakes of level 1 (i.e., small earthquakes), the displacement responses of the frame were tiny, like conventional frame behavior. Under earthquakes of level 2 (i.e., moderate earthquakes), a gap opening of the beam-column and column-base joints was observed. Under earthquakes of level 3 (i.e., large earthquakes), the gap opening of the joints was more evident. The concrete at the beam ends fell off because of the gap opening of the beam-column joints, as illustrated in Figures 11(a) and 11(b). Minor horizontal cracks developed at the column end stubs of the second story, as shown in Figure 11(c); these cracks were probably caused by the quality defects of the concrete pouring. No cracks were found on the concrete beams and columns.

Under earthquakes of level 4 , the structure and opened joints returned to their pre-earthquake positions. The number of minor horizontal cracks at the column end stubs of the 


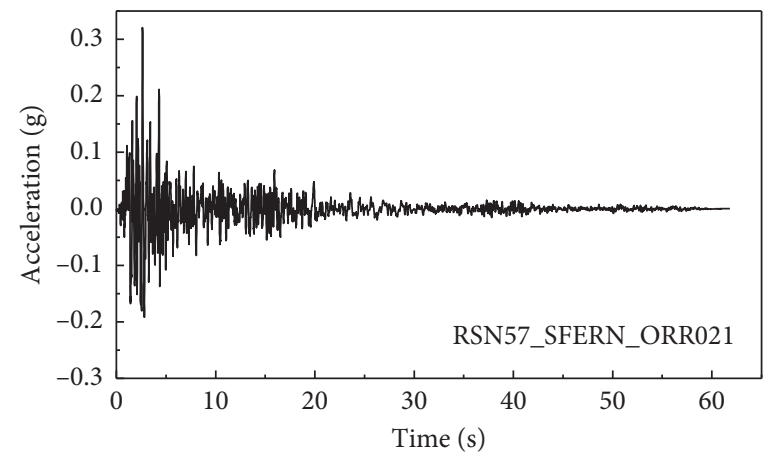

— SF (main)

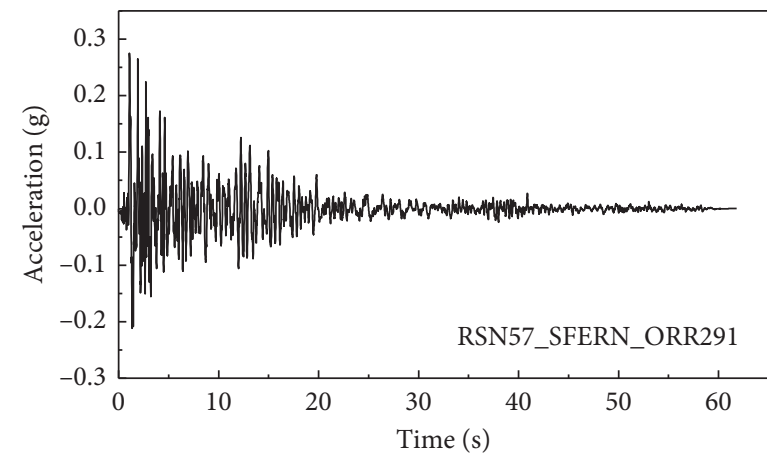

— SF (secondary)

(a)

(b)

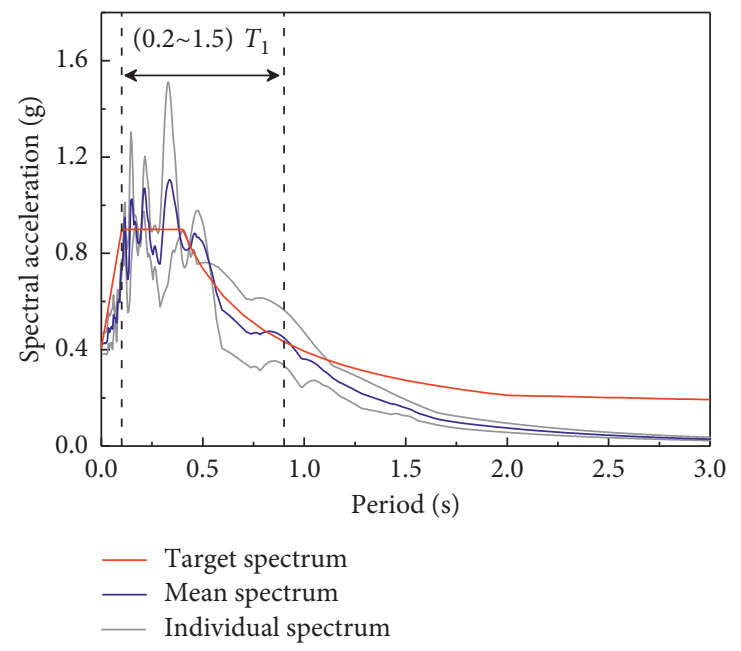

(c)

Figure 10: Acceleration time-history curves and spectral acceleration curves of the San Fernando earthquake. (a) Unscaled main excitation. (b) Unscaled secondary excitation. (c) Scaled acceleration spectra.

second story increased. The concrete cover under the embedded steel plate of the corbel began to fall off, as shown in Figure 12(a). The epoxy infilled in the MS damper (MC13) at the column-base joint (J04) began to leak out, as shown in Figure 12(b). The end of the MS damper (MB21) at the beamcolumn joint (J21) began to bend, as shown in Figure 12(c). The bolts used for fastening the MS dampers started to loosen and were retightened after each loading sequence.

Under earthquakes of level 5 , the structure and opened joints returned to their pre-earthquake positions. Part of the concrete under the embedded steel plate of the corbel began to crack, as shown in Figure 13(a). The epoxy filled in the MS damper (MC13) at the column-base joint (J04) began to leak out more seriously, as shown in Figure 13(b). The end of the MS damper (MB21) at the beam-column joint (J21) began to bend more seriously, as shown in Figure 13(c).

Under earthquakes of level 6, the structure and opened joints returned to their pre-earthquake positions. Vertical microcracks started developing on the concrete beams, as shown in Figure 14(a). Horizontal microcracks started developing on the concrete columns, and part of the concrete under the embedded steel plate of the corbel spalled out, as shown in Figure 14(b). During the loading process, a loud sound caused by steel plate collision was heard from the column-base joints.

Under earthquakes of level 7, the structure and opened joints returned to their pre-earthquake positions. The number of microcracks on the concrete beams and columns increased. Figures 15(a) and 15(b) show the vertical microcracks developed on beam-column joints J24 and J16, respectively. The gap opening of the column-base joint after the earthquakes was measured to be $5 \mathrm{~mm}$, as shown in Figure 15(c). It is noteworthy that the observed residual gap opening included a part that was attributed from the deformation of the column steel boot.

From the above test phenomenon, it can be qualitatively concluded that the damage to the self-centering frames installed in both the directions under all levels of earthquakes was very slight and that the structure could achieve self-centering after the earthquakes.

3.2. Dynamic Characteristics. The dynamic characteristics of the test structure were captured by the white noise tests performed. The first vibration mode of the structure was the translation along the structural $Y$ direction and the second 
TABLE 8: Test program.

\begin{tabular}{|c|c|c|c|}
\hline \multirow{2}{*}{ Sequence } & \multirow{2}{*}{ Input } & \multicolumn{2}{|c|}{ PGA (g) } \\
\hline & & $X$ & $Y$ \\
\hline 1 & WN1 & 0.10 & 0.10 \\
\hline 2 & SF1X & 0.13 & 0.11 \\
\hline 3 & SF1Y & 0.11 & 0.13 \\
\hline 4 & PA1X & 0.13 & 0.11 \\
\hline 5 & PA1Y & 0.11 & 0.13 \\
\hline 6 & WN2 & 0.10 & 0.10 \\
\hline 7 & WE1X & 0.13 & 0.11 \\
\hline 8 & WE1Y & 0.11 & 0.13 \\
\hline 9 & MH1X & 0.13 & 0.11 \\
\hline 10 & MH1Y & 0.11 & 0.13 \\
\hline 11 & WN3 & 0.10 & 0.10 \\
\hline 12 & SF2X & 0.26 & 0.22 \\
\hline 13 & SF2Y & 0.22 & 0.26 \\
\hline 14 & PA2X & 0.26 & 0.22 \\
\hline 15 & PA2Y & 0.22 & 0.26 \\
\hline 16 & WN4 & 0.10 & 0.10 \\
\hline 17 & WE2X & 0.26 & 0.22 \\
\hline 18 & WE2Y & 0.22 & 0.26 \\
\hline 19 & MH2X & 0.26 & 0.22 \\
\hline 20 & MH2Y & 0.22 & 0.26 \\
\hline 21 & WN5 & 0.10 & 0.10 \\
\hline 22 & SF3X & 0.52 & 0.44 \\
\hline 23 & SF3Y & 0.44 & 0.52 \\
\hline 24 & PA3X & 0.52 & 0.44 \\
\hline 25 & PA3Y & 0.44 & 0.52 \\
\hline 26 & WN6 & 0.10 & 0.10 \\
\hline 27 & WE3X & 0.52 & 0.44 \\
\hline 28 & WE3Y & 0.44 & 0.52 \\
\hline 29 & MH3X & 0.52 & 0.44 \\
\hline 30 & MH3Y & 0.44 & 0.52 \\
\hline 31 & WN7 & 0.10 & 0.10 \\
\hline 32 & SF4X & 0.78 & 0.66 \\
\hline 33 & SF4Y & 0.66 & 0.78 \\
\hline 34 & PA4X & 0.78 & 0.66 \\
\hline 35 & PA4Y & 0.66 & 0.78 \\
\hline 36 & WN8 & 0.10 & 0.10 \\
\hline 37 & WE4X & 0.78 & 0.66 \\
\hline 38 & WE4Y & 0.66 & 0.78 \\
\hline 39 & MH4X & 0.78 & 0.66 \\
\hline 40 & MH4Y & 0.66 & 0.78 \\
\hline 41 & WN9 & 0.10 & 0.10 \\
\hline 42 & SF5X & 1.04 & 0.88 \\
\hline 43 & SF5Y & 0.88 & 1.04 \\
\hline 44 & WN10 & 0.10 & 0.10 \\
\hline 45 & PA5X & 1.04 & 0.88 \\
\hline 46 & PA5Y & 0.88 & 1.04 \\
\hline 47 & WN11 & 0.10 & 0.10 \\
\hline 48 & WE5X & 1.04 & 0.88 \\
\hline 49 & WE5Y & 0.88 & 1.04 \\
\hline 50 & WN12 & 0.10 & 0.10 \\
\hline 51 & MH5X & 1.04 & 0.88 \\
\hline 52 & MH5Y & 0.88 & 1.04 \\
\hline 53 & WN13 & 0.10 & 0.10 \\
\hline 54 & SF6X & 1.30 & 1.11 \\
\hline 55 & SF6Y & 1.11 & 1.30 \\
\hline 56 & WN14 & 0.10 & 0.10 \\
\hline 57 & PA6X & 1.30 & 1.11 \\
\hline 58 & PA6Y & 1.11 & 1.30 \\
\hline 59 & WN15 & 0.10 & 0.10 \\
\hline
\end{tabular}

TABle 8: Continued.

\begin{tabular}{lccc}
\hline Sequence & Input & \multicolumn{2}{c}{ PGA (g) } \\
\hline 60 & WE6X & 1.30 & $Y$ \\
61 & WE6Y & 1.11 & 1.11 \\
62 & WN16 & 0.10 & 0.10 \\
63 & MH6X & 1.30 & 1.11 \\
64 & MH6Y & 1.11 & 1.30 \\
65 & WN17 & 0.10 & 0.10 \\
66 & SF7X & 1.56 & 1.33 \\
67 & SF7Y & 1.33 & 1.56 \\
68 & WN18 & 0.10 & 0.10 \\
69 & PA7X & 1.56 & 1.33 \\
70 & PA7Y & 1.33 & 1.56 \\
71 & WN19 & 0.10 & 0.10 \\
72 & WE7X & 1.56 & 1.33 \\
73 & WE7Y & 1.33 & 1.56 \\
74 & WN20 & 0.10 & 0.10 \\
75 & MH7X & 1.56 & 1.33 \\
76 & MH7Y & 1.33 & 1.56 \\
77 & WN21 & 0.10 & 0.10 \\
\hline
\end{tabular}

WN1 represents the first white noise scanning undertaken. SF1X, PA1X, WE1X, and MH1X refer to the hazard level 1 of San Fernando, Parkfield02_CA, Wenchuan, and Morgan Hill earthquakes, respectively, with the main excitation applied along the structural $X$ direction.

was the translation along the structural $X$ direction. Figure 16(a) shows the natural frequencies in both the directions of each white noise sequence. The natural frequencies decreased gradually with the increase in the amplitude of ground motions. This trend indicated that the structural stiffness degraded progressively during the test, as the result of the prestress loss of the PT steel wires, yielding of the MS dampers, and minor cracks that developed on the concrete beams and columns. Figure 16(b) compares the relative changes in average natural frequency in both the directions under each seismic hazard level. The initial values of natural frequency were 3.66 and $3.82 \mathrm{~Hz}$, which indicated that the initial stiffness of the $Y$-direction frame was a little smaller than that of the $X$-direction frame. Moreover, the lateral stiffness of the $Y$-direction frame reduced more rapidly than that of the $X$-direction frame. After large earthquakes with a PGA of $0.52 \mathrm{~g}$, the frequencies were 3.04 and $3.54 \mathrm{~Hz}$, decreased by $17.0 \%$ and $7.4 \%$. The frequencies were 2.66 and $3.16 \mathrm{~Hz}$ at the end of loading, decreased by $27.5 \%$ and $17.1 \%$.

3.3. Displacement Response. The structural floor displacements under each hazard level of the four earthquakes (SF, $\mathrm{PA}, \mathrm{WE}$, and $\mathrm{MH}$ ) were investigated. Figure 17 shows the maximum floor displacements relative to the base in both the structural $X$ and $Y$ directions. Overall, the maximum floor displacements in the two directions increased as the severity of the seismic hazard levels increased. The floor displacement responses of the $Y$-direction frame installed with MS dampers were larger than those of the $X$-direction frame installed with angle steels because of the smaller lateral stiffness of the $Y$-direction frame than the $X$-direction frame. 


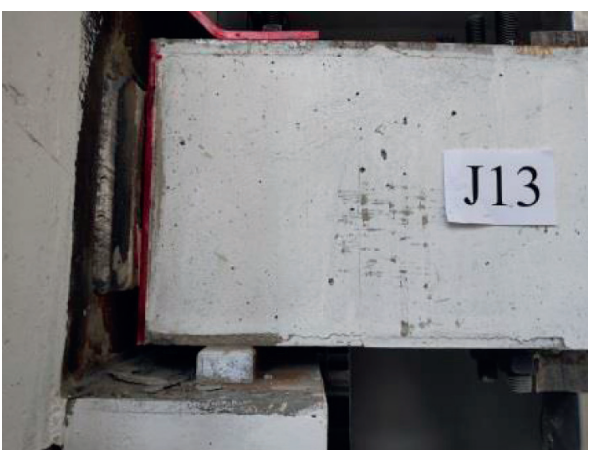

(a)

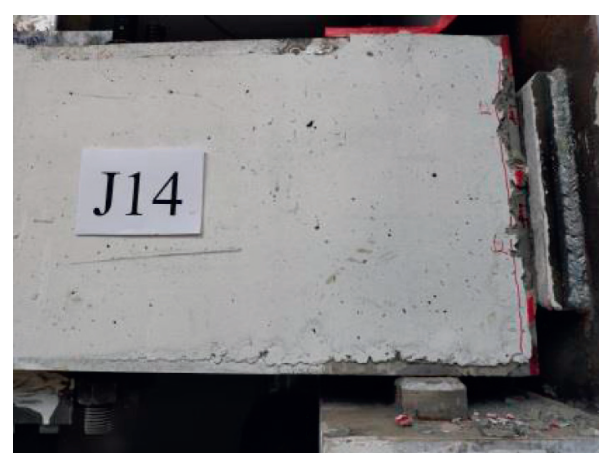

(b)

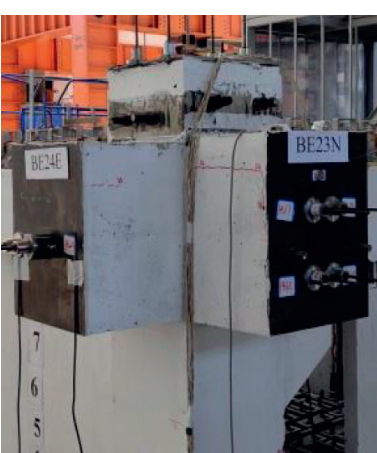

(c)

Figure 11: Typical test phenomenon after earthquakes of level 3. (a) Thin layer of concrete between steel plates of beam end and column at the beam-column joint (J13) falling off. (b) Concrete cover of beam end at the beam-column joint (J14) falling off. (c) Minor horizontal cracks developing at stubs of the second story.

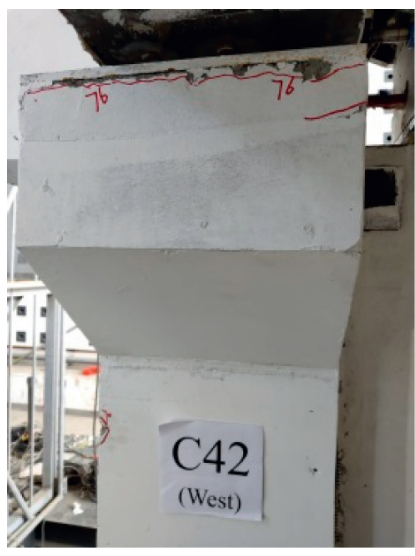

(a)

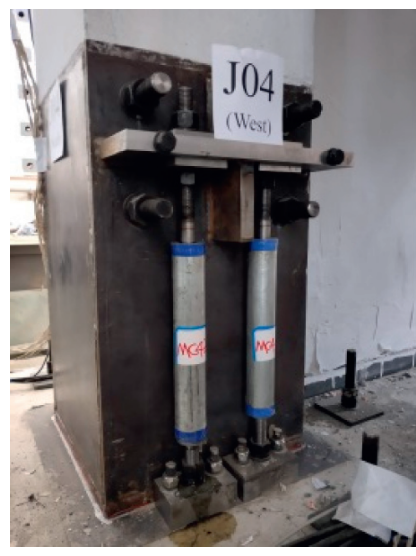

(b)

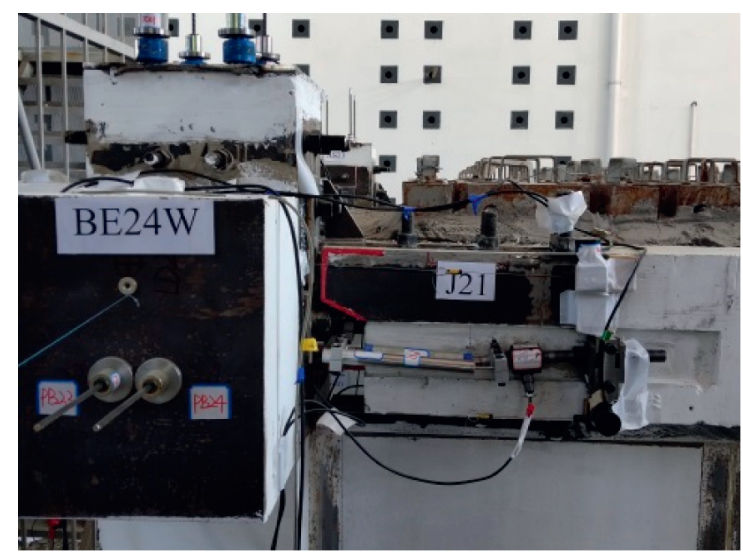

(c)

Figure 12: Typical test phenomenon after earthquakes of level 4. (a) Concrete cover under the steel plate of concrete corbel falling off. (b) Epoxy in the MS damper (MC13) at the column-base joint (J04) leaking out. (c) End of the MS damper (MB21) at the beam-column joint (J21) bending.

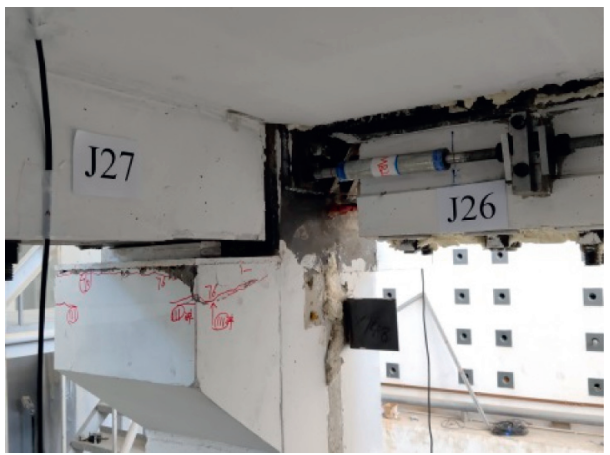

(a)

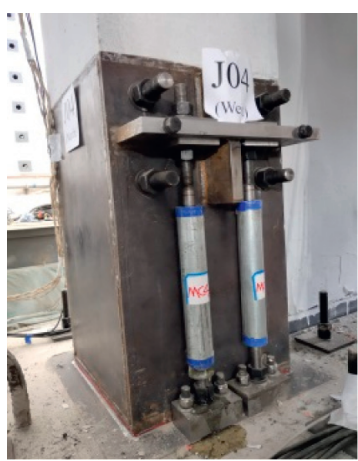

(b)

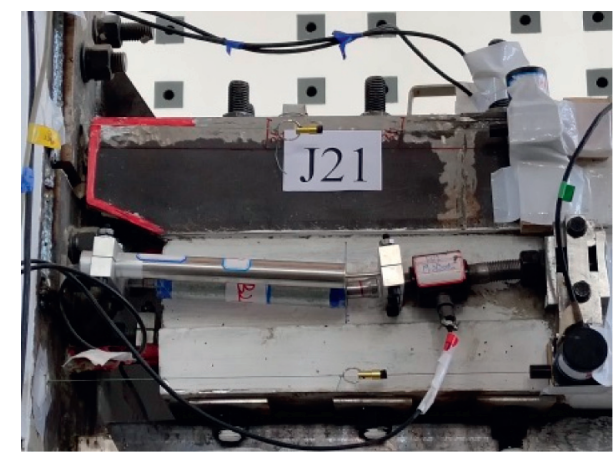

(c)

FIGURE 13: Typical test phenomenon after earthquakes of level 5. (a) Part of concrete under the embedded steel plate of corbel cracking. (b) Epoxy in the MS damper (MC13) leaking out more seriously. (c) End of the MS damper (MB21) bending more seriously.

Figure 18 illustrates the maximum interstory drifts of the test structure. The interstory drifts continually increased in both directions. The drifts increased to $2.47 \%$ and $3.18 \%$ in the $X$ and $Y$ directions, respectively, under earthquakes of level $7(\mathrm{PGA}=1.56 \mathrm{~g})$. The drifts were higher than the $2.0 \%$ limit for conventional RC frames prescribed in the Chinese seismic design code [23]. However, at this stage, the damage to the main frames installed in both the directions was still 


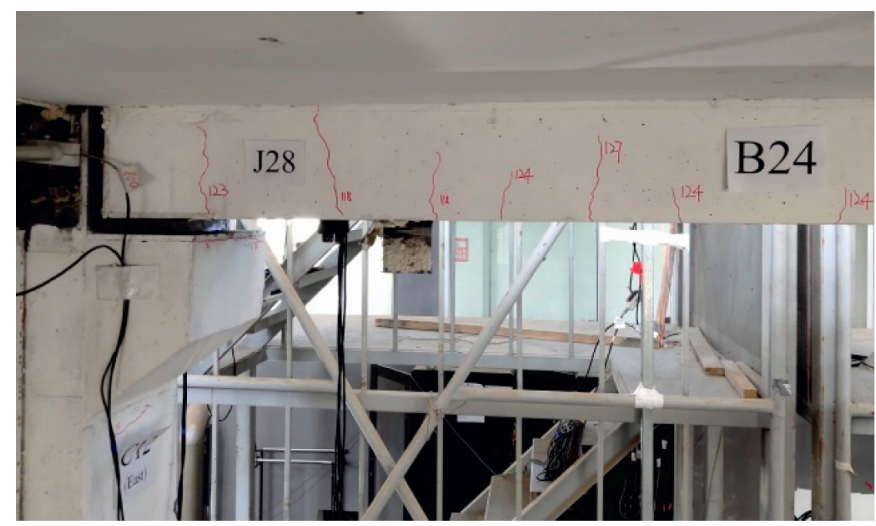

(a)

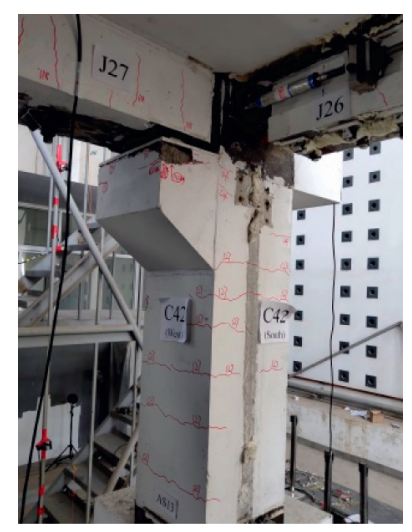

(b)

Figure 14: Typical test phenomenon after earthquakes of level 6. (a) Vertical microcracks on the concrete beam (B24). (b) Horizontal microcracks on the concrete column (C42).

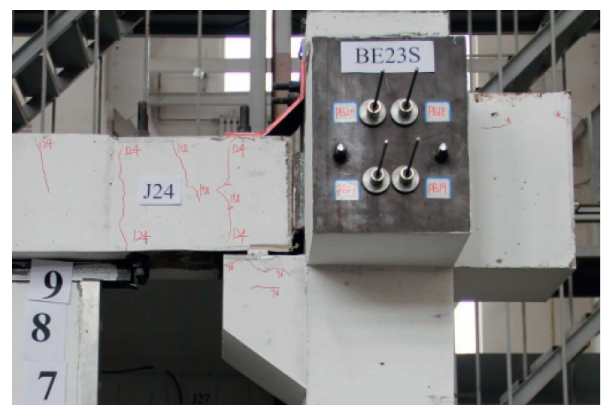

(a)

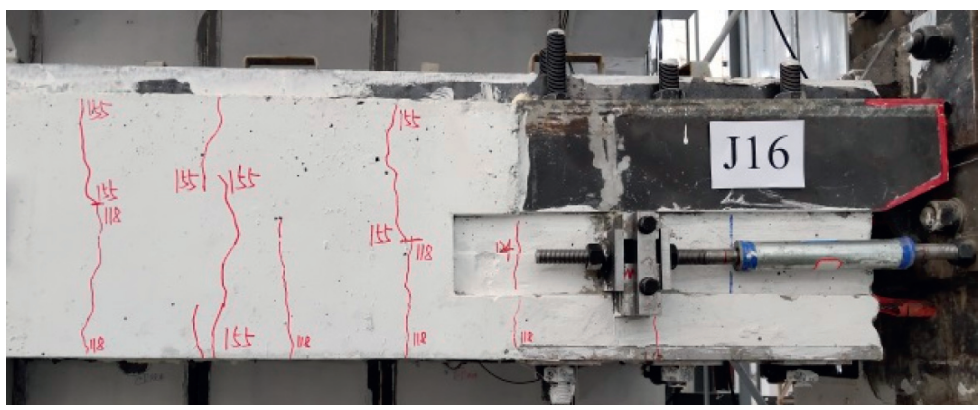

(b)

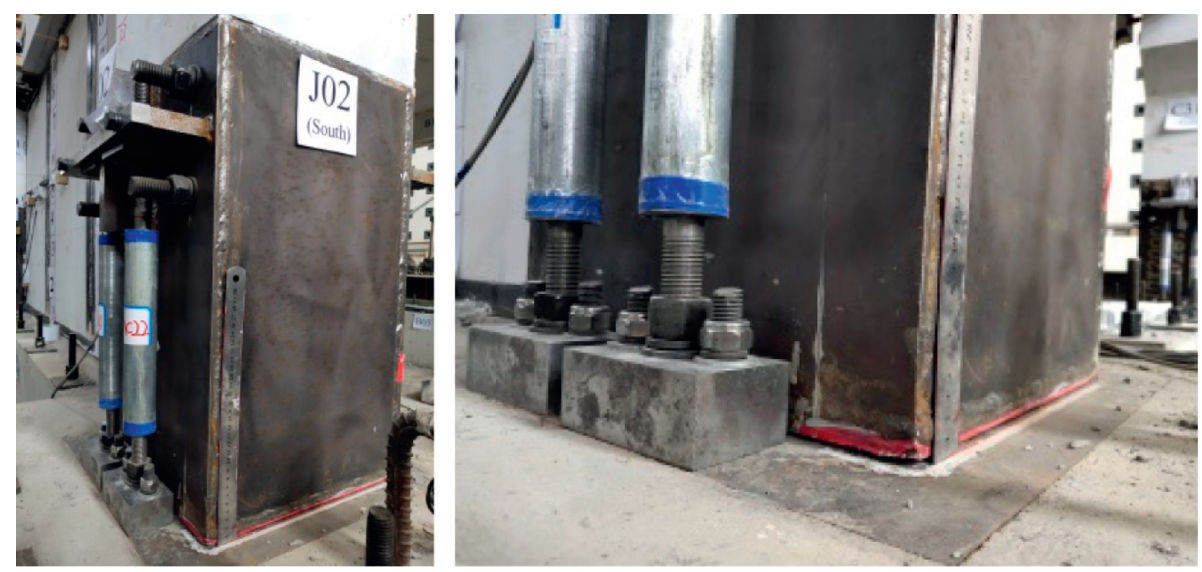

(c)

FIgURE 15: Typical test phenomenon after earthquakes of level 7. (a) Vertical microcracks at the beam-column joint (J24). (b) Vertical microcracks at the beam-column joint (J16). (c) Gap opening of the column-base joint (J02).

not severe and only some microcracks had developed on the RC beams and columns, as specified in Section 3.1.

The displacement responses under the four earthquakes were then compared to obtain the maximum displacement responses of the test structure, as summarized in Table 9. Both the residual floor displacements and residual interstory drifts in the two directions did not increase considerably with the increasing hazard level of the ground motions; this trend was different from that of the maximum displacement responses. The ratio of the residual interstory drifts to the maximum values was $3.64 \%$ and $2.15 \%$ in the $X$ and $Y$ directions, respectively, under earthquakes of level 1 $(\mathrm{PGA}=0.13 \mathrm{~g})$ and decreased to $1.83 \%$ and $0.78 \%$, respectively, under earthquakes of level $7(\mathrm{PGA}=1.56 \mathrm{~g})$.

Figure 19 shows the time-history curves of the top floor displacements in the two directions under Parkfield-02_CA earthquake excitations when the PGA was $1.56 \mathrm{~g}$. The residual floor displacement was negligible although the 


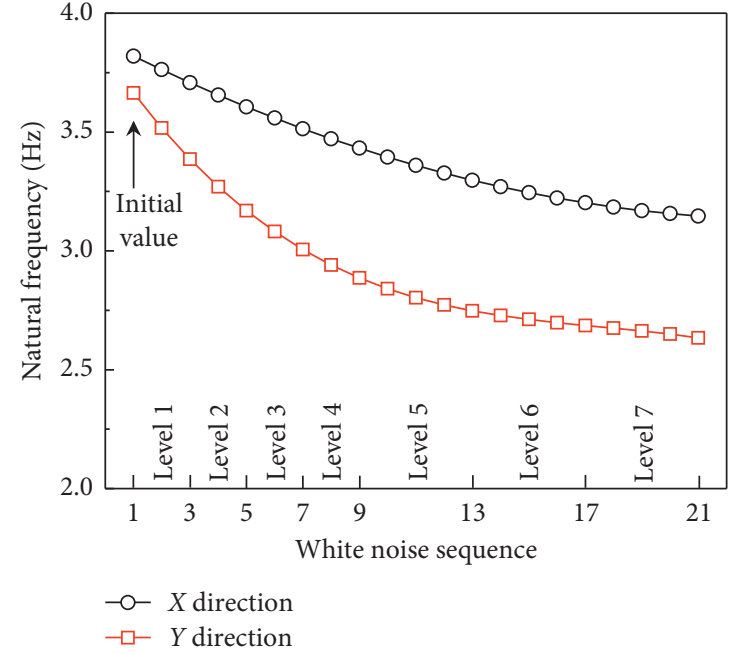

(a)

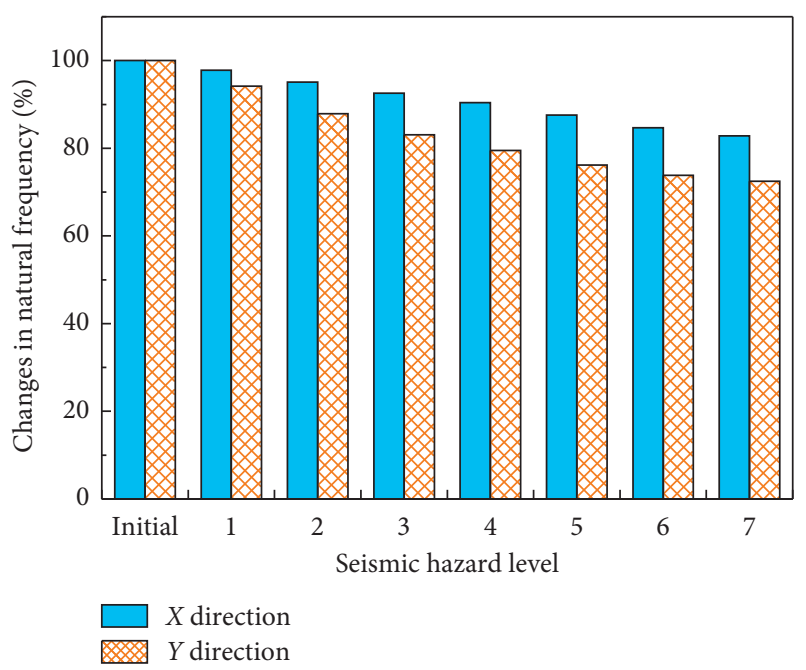

(b)

Figure 16: Natural frequencies of the test structure. (a) Natural frequencies in both the directions. (b) Relative changes in natural frequency under each seismic hazard level.

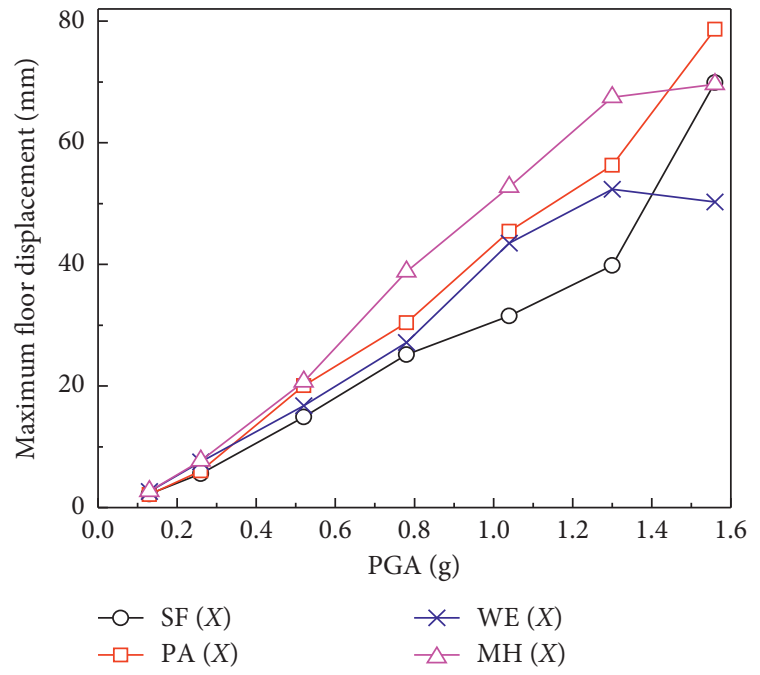

(a)

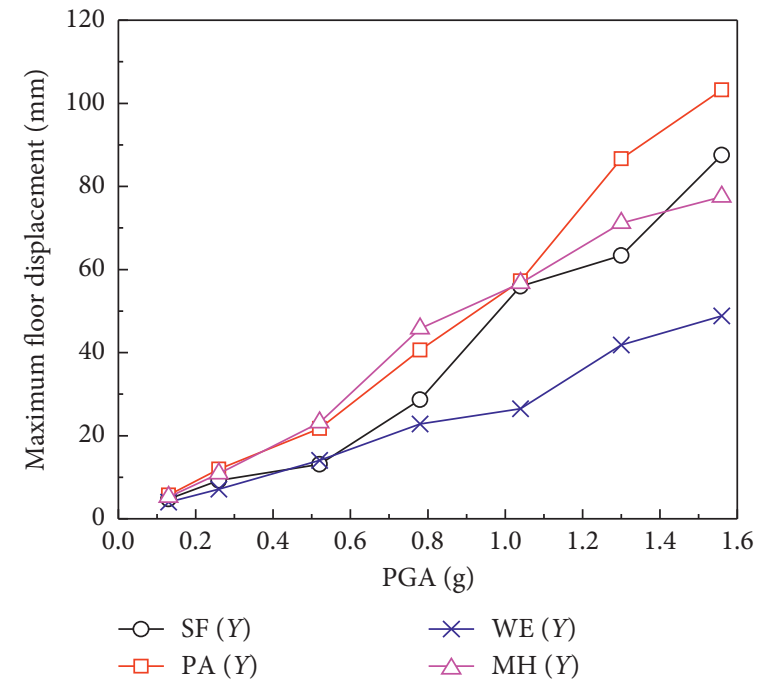

(b)

Figure 17: Maximum floor displacements. (a) X-direction frame. (b) Y-direction frame.

maximum displacements were 78.65 and $103.20 \mathrm{~mm}$ in the $X$ and $Y$ directions, respectively.

The above results showed that although the structure endured large deformations under strong ground motions, the frames installed in both directions could achieve selfcentering thoroughly.

3.4. Acceleration Response. The floor accelerations were obtained using the acceleration transducers installed at each floor. Figure 20 shows the maximum floor accelerations of the test structure. Overall, the maximum floor acceleration in both directions increased as the severity of the seismic hazard levels increased. The floor accelerations of the frame with MS dampers
( $Y$ direction) were lower than those of the frame with angle steels ( $X$ direction) because of the weakened lateral stiffness of the $Y$ direction frame. The acceleration amplification factor was defined to quantify the acceleration amplification effect of each floor:

$$
K A_{i}=\frac{A F_{i}}{A F_{0}},
$$

where $A F_{0}$ is the maximum acceleration at the base of the test structure (unit: $\mathrm{g}$ ), $A F_{i}$ is the maximum acceleration of the $i$ th floor (unit: $\mathrm{g}$ ), and $K A_{i}$ is the acceleration amplification factor of the $i$ th floor.

Figure 21 shows the maximum amplification factor of the floor acceleration in both the $X$ and $Y$ directions. The 


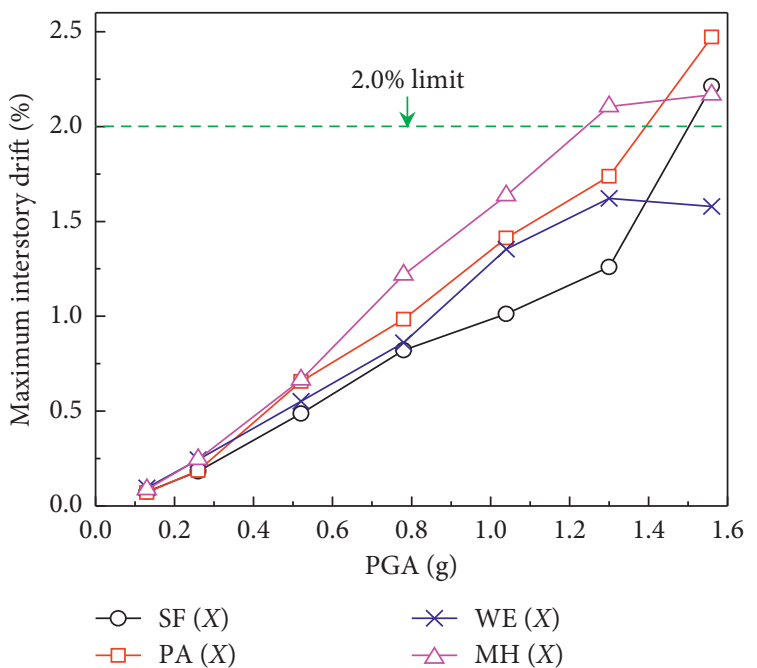

(a)

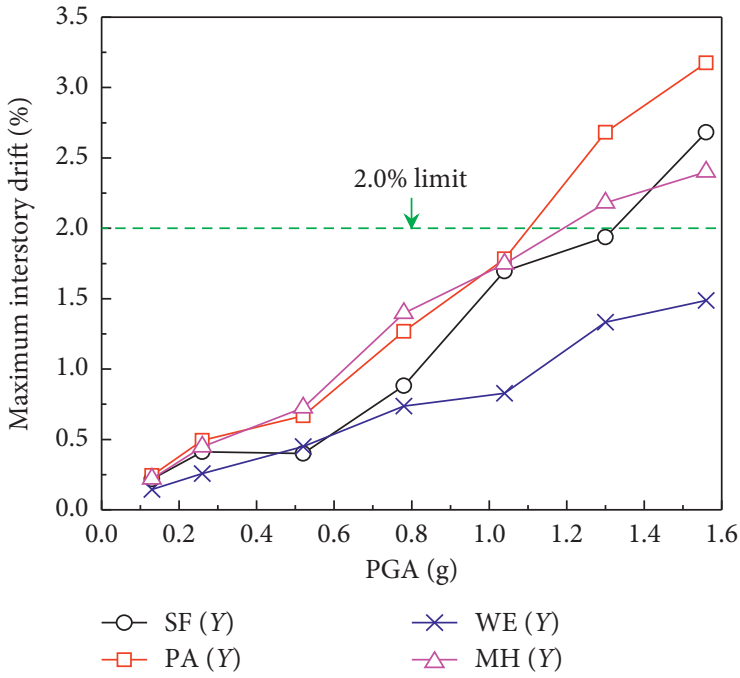

(b)

Figure 18: Maximum interstory drifts. (a) $X$-direction frame. (b) $Y$-direction frame.

TABLE 9: Maximum displacement responses of the test structure.

\begin{tabular}{|c|c|c|c|c|c|c|c|c|}
\hline \multirow[t]{2}{*}{ PGA（g) } & \multicolumn{2}{|c|}{$\begin{array}{c}\text { Maximum floor } \\
\text { displacement }(\mathrm{mm})\end{array}$} & \multicolumn{2}{|c|}{$\begin{array}{l}\text { Maximum residual } \\
\text { floor displacement } \\
(\mathrm{mm})\end{array}$} & \multicolumn{2}{|c|}{$\begin{array}{l}\text { Maximum } \\
\text { interstory drift (\%) }\end{array}$} & \multicolumn{2}{|c|}{$\begin{array}{l}\text { Maximum residual } \\
\text { interstory drift (\%) }\end{array}$} \\
\hline & $X$ & $Y$ & $X$ & $Y$ & $X$ & $Y$ & $X$ & $Y$ \\
\hline 0.13 & 2.70 & 5.70 & 0.07 & 0.15 & 0.10 & 0.24 & 0.00 & 0.01 \\
\hline 0.26 & 7.71 & 11.93 & 0.19 & 0.28 & 0.25 & 0.49 & 0.01 & 0.01 \\
\hline 0.52 & 20.68 & 23.17 & 0.46 & 0.80 & 0.66 & 0.73 & 0.02 & 0.03 \\
\hline 0.78 & 38.81 & 45.75 & 0.78 & 0.54 & 1.22 & 1.40 & 0.03 & 0.02 \\
\hline 1.04 & 52.71 & 57.27 & 0.94 & 0.99 & 1.64 & 1.78 & 0.03 & 0.03 \\
\hline 1.30 & 67.48 & 86.64 & 1.07 & 0.88 & 2.11 & 2.68 & 0.04 & 0.03 \\
\hline 1.56 & 78.65 & 103.20 & 1.23 & 0.66 & 2.47 & 3.18 & 0.05 & 0.02 \\
\hline
\end{tabular}

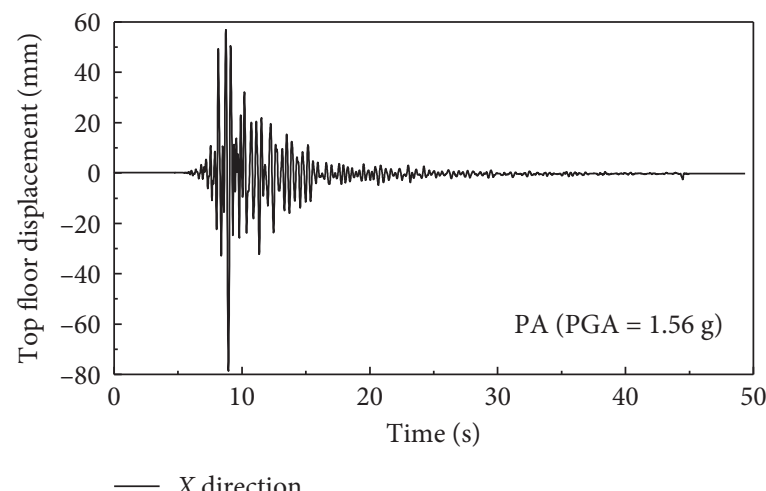

(a)

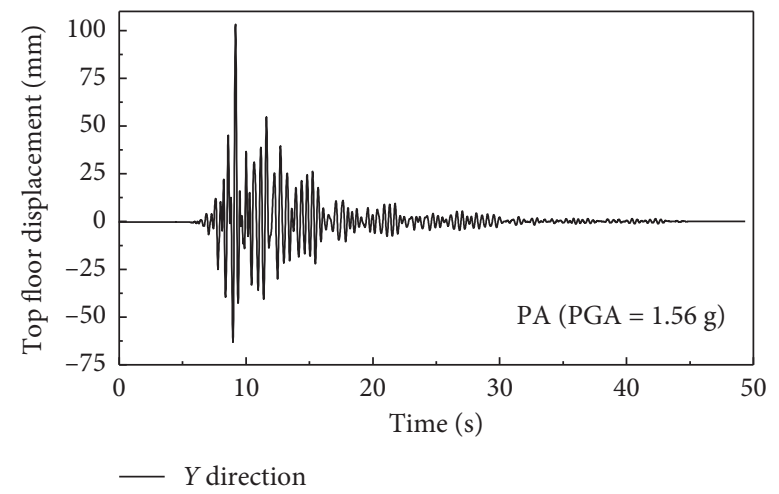

(b)

Figure 19: Top floor displacement curves under Parkfield-02_CA earthquakes. (a) X-direction frame. (b) $Y$-direction frame.

acceleration amplification factors decreased as the severity of the seismic hazard levels increased, which indicated that the lateral stiffness of the frames gradually reduced in both the directions because of the prestress loss of the PT steel wires, yielding of the MS dampers, and minor cracks that developed on the concrete beams and columns.
Table 10 summarizes the maximum floor acceleration responses of the test structure under the four earthquakes. From the perspective of the average ratio of all the seismic hazard levels, the maximum acceleration in the $X$ direction was approximately 1.10 times that in the $Y$ direction. The maximum acceleration of the second floor was approximately 


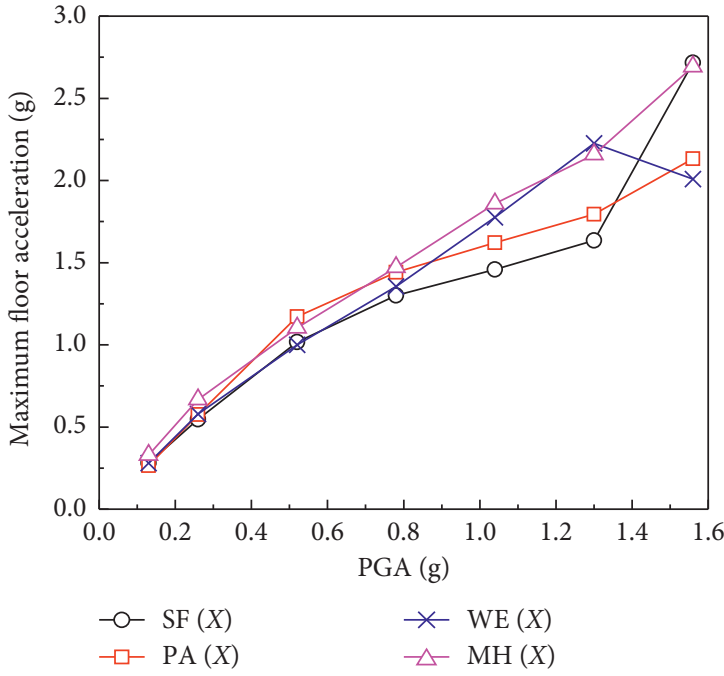

(a)

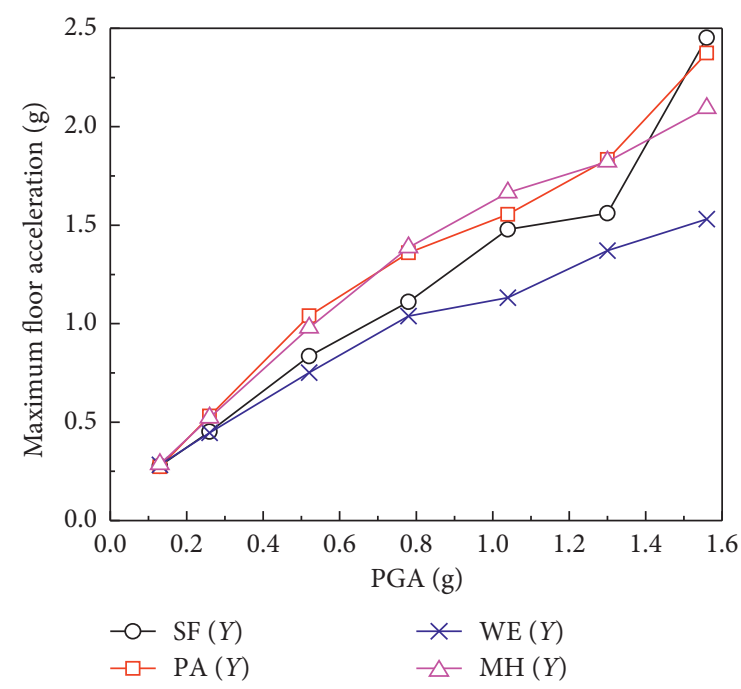

(b)

FIgURE 20: Maximum floor accelerations. (a) X-direction frame. (b) $Y$-direction frame.

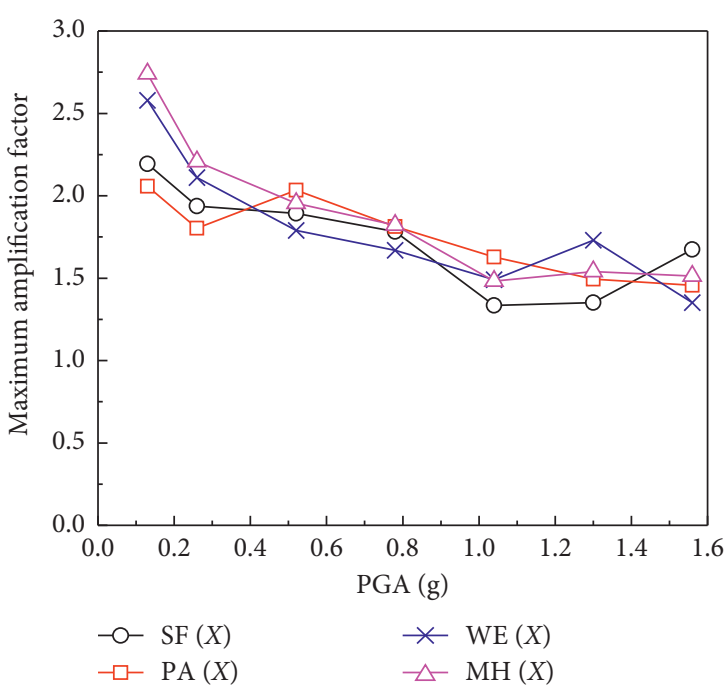

(a)

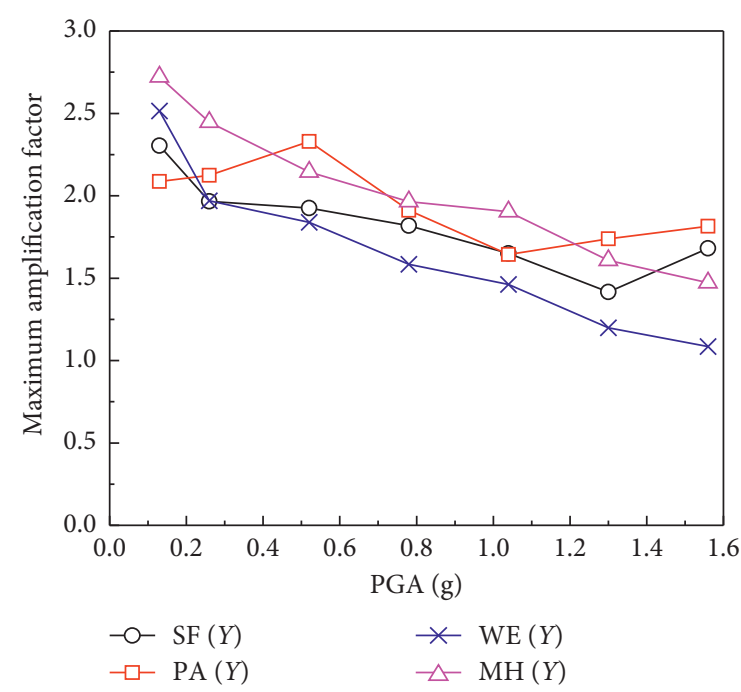

(b)

FIGURE 21: Maximum acceleration amplification factors. (a) $X$-direction frame. (b) $Y$-direction frame.

TABLE 10: Maximum acceleration responses of the test structure.

\begin{tabular}{|c|c|c|c|c|c|c|c|c|}
\hline \multirow[t]{2}{*}{ PGA (g) } & \multicolumn{2}{|c|}{$\begin{array}{l}\text { Maximum } 1^{\text {st }} \text { floor } \\
\text { acceleration }(\mathrm{g})\end{array}$} & \multicolumn{2}{|c|}{$\begin{array}{l}\text { Maximum } 2^{\text {nd }} \text { floor } \\
\text { acceleration }(\mathrm{g})\end{array}$} & \multicolumn{2}{|c|}{$\begin{array}{l}\text { Maximum } 1^{\text {st }} \text { floor } \\
\text { amplification factor }\end{array}$} & \multicolumn{2}{|c|}{$\begin{array}{l}\text { Maximum } 2^{\text {nd }} \text { floor } \\
\text { amplification factor }\end{array}$} \\
\hline & $X$ & $Y$ & $X$ & $Y$ & $X$ & $Y$ & $X$ & $Y$ \\
\hline 0.13 & 0.21 & 0.17 & 0.33 & 0.29 & 1.79 & 1.51 & 2.74 & 2.72 \\
\hline 0.26 & 0.51 & 0.44 & 0.67 & 0.53 & 1.76 & 1.97 & 2.21 & 2.45 \\
\hline 0.52 & 0.67 & 0.65 & 1.17 & 1.04 & 1.51 & 1.46 & 2.03 & 2.33 \\
\hline 0.78 & 0.94 & 0.83 & 1.47 & 1.39 & 1.19 & 1.18 & 1.82 & 1.96 \\
\hline 1.04 & 1.11 & 1.41 & 1.86 & 1.66 & 1.11 & 1.63 & 1.63 & 1.90 \\
\hline 1.30 & 1.80 & 1.59 & 2.23 & 1.83 & 1.49 & 1.51 & 1.73 & 1.74 \\
\hline 1.56 & 1.59 & 1.76 & 2.72 & 2.45 & 1.06 & 1.34 & 1.67 & 1.81 \\
\hline
\end{tabular}




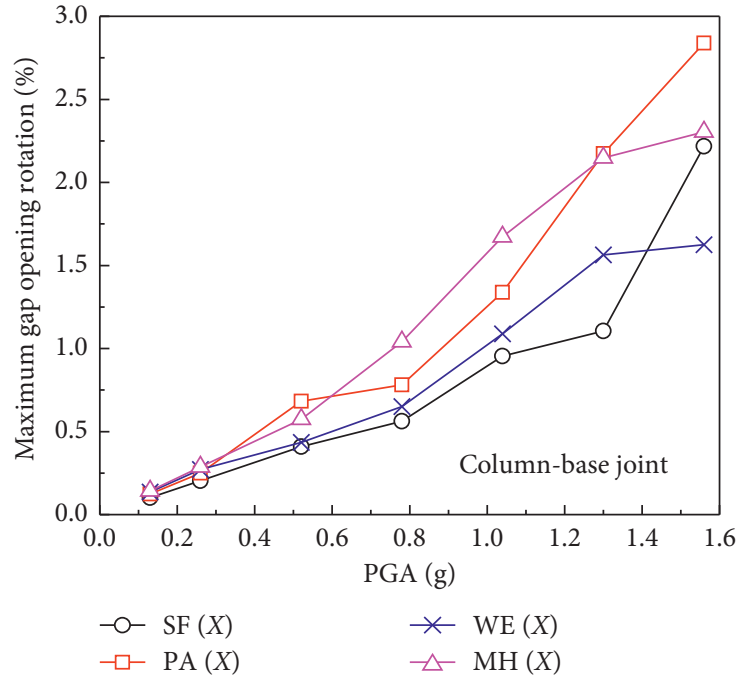

(a)

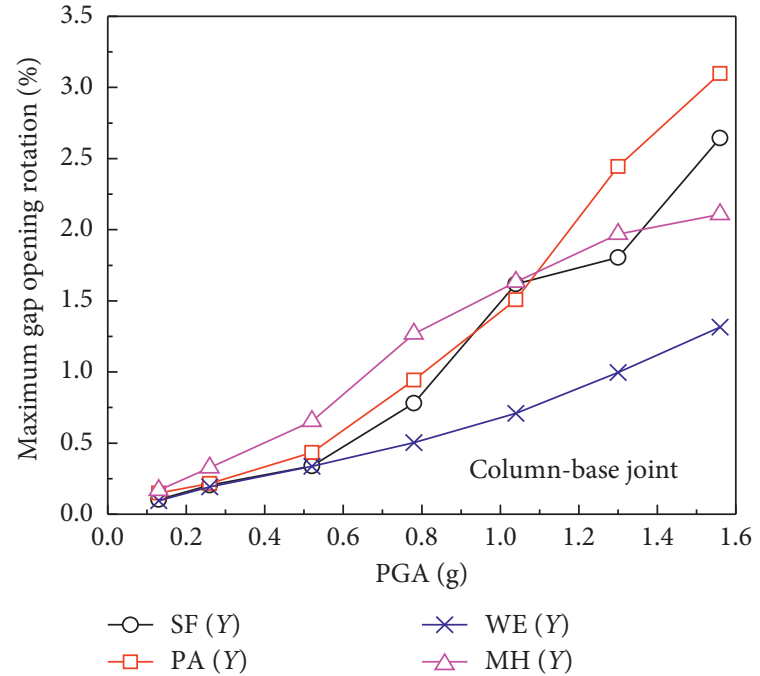

(b)

Figure 22: Maximum gap opening rotation of column-base joints. (a) In $X$ direction. (b) In $Y$ direction.

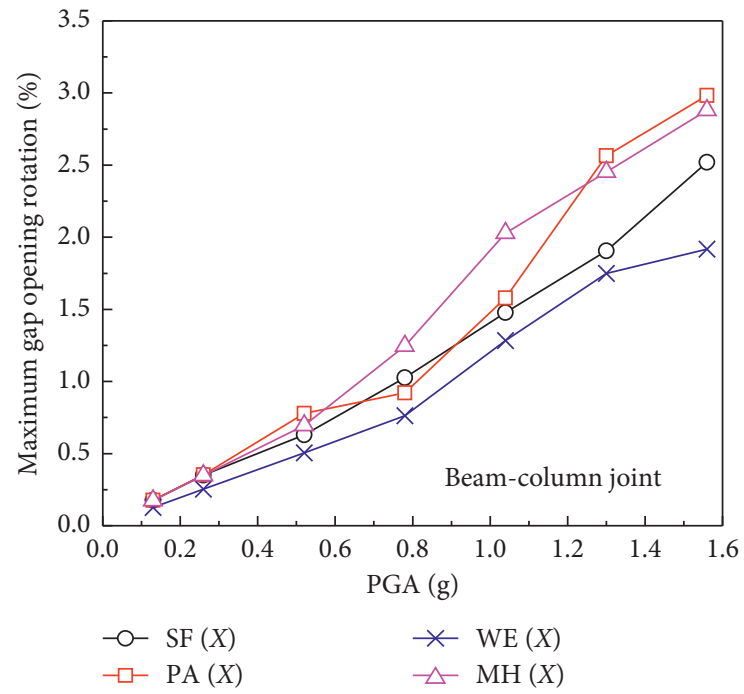

(a)

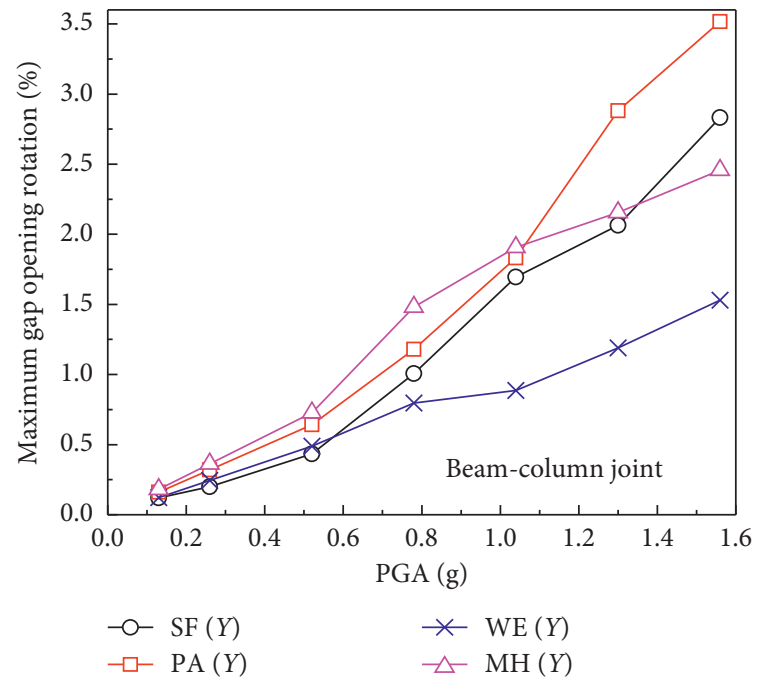

(b)

FIgure 23: Maximum gap opening rotation of beam-column joints. (a) In $X$ direction. (b) In $Y$ direction.

1.48 times that of the first floor. The maximum amplification factors ranged from 1.0 to 1.8 for the first floor and from 1.6 to 2.8 for the second floor. The largest acceleration amplification factors were 2.74 and 2.72 in the $X$ and $Y$ directions, respectively; these values were obtained for the second floor of the structure under the Morgan Hill earthquakes of level 1 (PGA $=0.13 \mathrm{~g})$.

3.5. Gap Opening Rotation. The gap opening displacement of the column-base and beam-column joints was monitored using displacement transducers installed at the column bottom and beam ends, as illustrated in Figure 4. The gap opening rotation of the joints was obtained by dividing the displacement difference by the distance between the two sensors on the same side.

Figures 22 and 23 show the maximum gap opening rotation of the column-base and beam-column joints, respectively, in both the $X$ and $Y$ directions. The maximum gap opening rotation in both the directions increased as the severity of the seismic hazard levels increased. The values of the maximum gap opening rotation in both the directions were approximately equal to the corresponding maximum interstory drifts, as shown in Figure 18. The results indicated that the structural deformation was mainly concentrated at the column-base and beam-column joints, and hence, damage to the concrete beams and columns was considerably alleviated, as described in Section 3.1. 
TABLE 11: Maximum gap opening rotation of joints.

\begin{tabular}{|c|c|c|c|c|c|c|c|c|}
\hline \multirow[t]{2}{*}{ PGA (g) } & \multicolumn{2}{|c|}{$\begin{array}{l}\text { Maximum rotation } \\
\text { of column-base } \\
\text { joints (\%) }\end{array}$} & \multicolumn{2}{|c|}{$\begin{array}{l}\text { Maximum residual } \\
\text { rotation of column- } \\
\text { base joints (\%) }\end{array}$} & \multicolumn{2}{|c|}{$\begin{array}{l}\text { Maximum rotation } \\
\text { of beam-column } \\
\text { joints }(\%)\end{array}$} & \multicolumn{2}{|c|}{$\begin{array}{l}\text { Maximum residual } \\
\text { rotation of beam- } \\
\text { column joints (\%) }\end{array}$} \\
\hline & $X$ & $Y$ & $X$ & $Y$ & $X$ & $Y$ & $X$ & $Y$ \\
\hline 0.13 & 0.14 & 0.17 & 0.03 & 0.03 & 0.18 & 0.18 & 0.03 & 0.05 \\
\hline 0.26 & 0.29 & 0.33 & 0.03 & 0.03 & 0.38 & 0.30 & 0.05 & 0.07 \\
\hline 0.52 & 0.68 & 0.65 & 0.04 & 0.03 & 0.78 & 0.73 & 0.05 & 0.05 \\
\hline 0.78 & 1.04 & 1.27 & 0.04 & 0.03 & 1.25 & 1.48 & 0.06 & 0.07 \\
\hline 1.04 & 1.67 & 1.63 & 0.07 & 0.04 & 2.03 & 1.91 & 0.07 & 0.06 \\
\hline 1.30 & 2.17 & 2.44 & 0.06 & 0.04 & 2.56 & 2.88 & 0.07 & 0.05 \\
\hline 1.56 & 2.84 & 3.10 & 0.09 & 0.05 & 2.98 & 3.52 & 0.08 & 0.06 \\
\hline
\end{tabular}

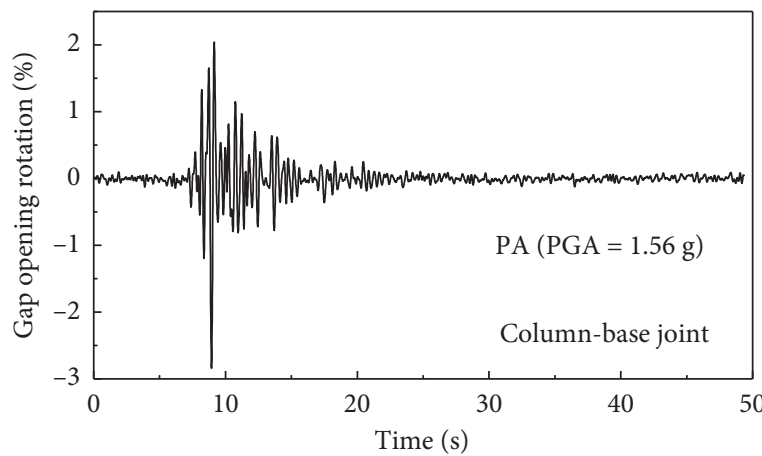

$-X$ direction

(a)

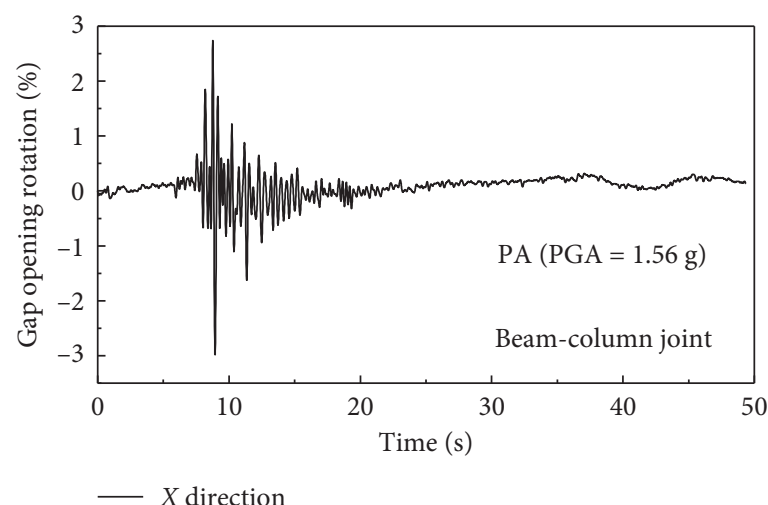

(c)

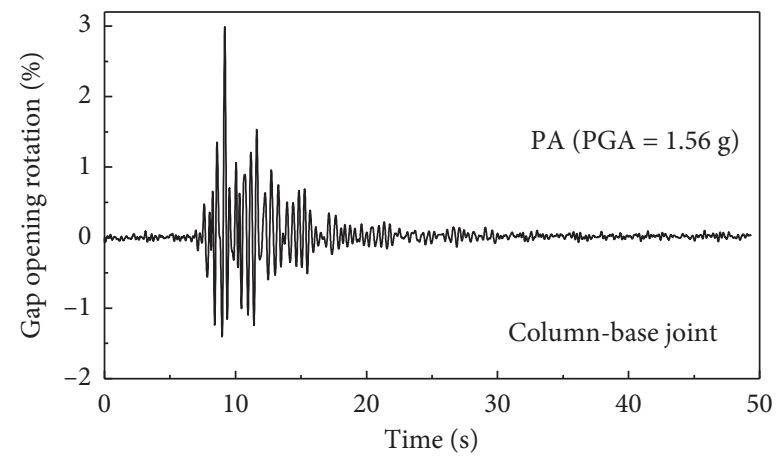

- $Y$ direction

(b)

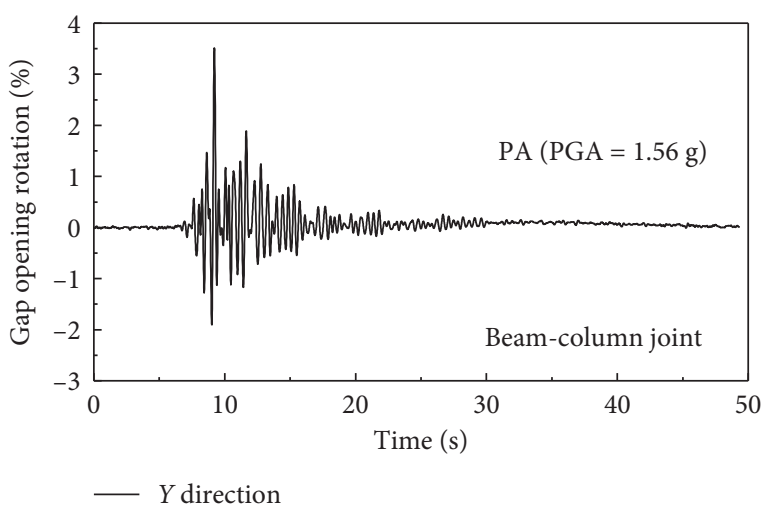

(d)

Figure 24: Time-history curves of gap opening rotation under Parkfield-02_CA earthquakes. (a) Column-base joint (J01) in the $X$ direction. (b) Column-base joint (J01) in the $Y$ direction. (c) Beam-column joint (J18) in the $X$ direction. (d) Beam-column joint (J11) in the $Y$ direction.

Table 11 summarizes the maximum gap opening rotation of the joints under the four earthquakes. The gaps in both the column-base and beam-column joints began to open slightly under small earthquakes and continuously increased as the intensity of the ground motions increased. However, the maximum residual gap opening rotation of the joints remained below $0.1 \%$; this trend was different from that of the maximum gap opening rotation responses.

Figures 24(a) and 24(b) show the time-history curves of the gap opening rotation of a column-base joint (J01) in the structural $X$ and $Y$ directions, respectively, under Parkfield-
02_CA earthquakes of level $7(\mathrm{PGA}=1.56 \mathrm{~g})$. The maximum gap opening rotation was $2.84 \%$ and $3.10 \%$, but the residual gap rotation was just $0.03 \%$ and $0.04 \%$. Figures $24(\mathrm{c})$ and 24(d) show the time-history curves of the gap opening rotation of the beam-column joints in the $X$ and $Y$ directions, respectively, under Parkfield-02_CA earthquakes of level $7(\mathrm{PGA}=1.56 \mathrm{~g})$. The maximum gap opening rotation reached $2.98 \%$ and $3.52 \%$, but the residual gap rotation was only $0.06 \%$ and $0.02 \%$.

The above results indicated that the column-base and beam-column joints could open effectively and that 


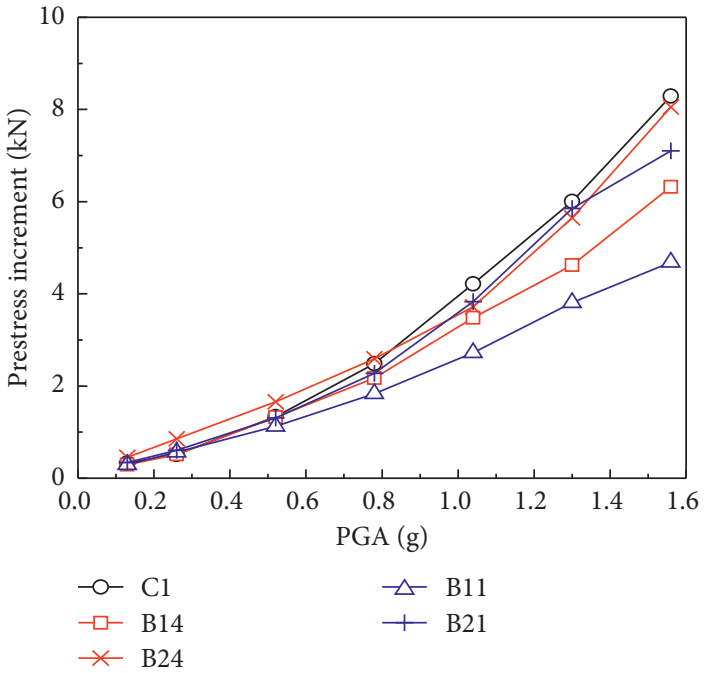

(a)

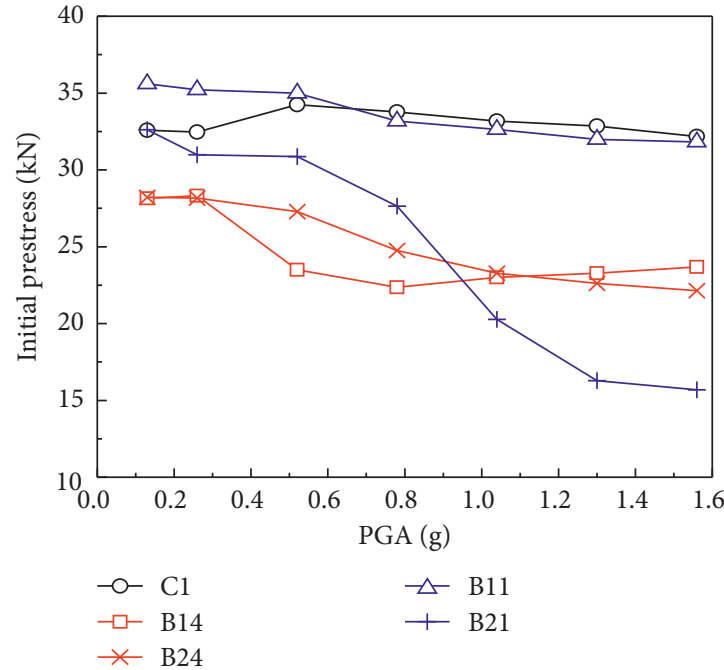

(b)

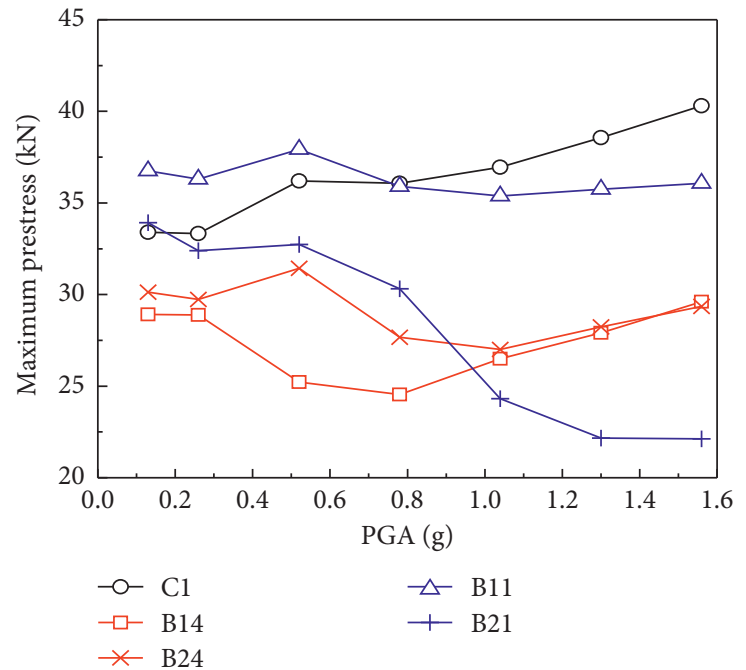

(c)

Figure 25: Axial forces of PT steel wires. (a) Prestress increment. (b) Initial prestress. (c) Maximum prestress.

structural deformation was mainly concentrated at the joints. After each level of earthquake excitations, the joints in both the directions returned to their original positions with negligible residual gap displacement.

3.6. Axial Forces of PT Steel Wires. The axial forces of PT steel wires that passed through the RC beams and columns were obtained by load cells, as shown in Figure 4. Figure 25 shows the average values of prestress increment, initial prestress and maximum prestress of the PT steel wires in column (C1) and beams (B14, B24, B11, and B21) under the four earthquakes. The prestress increment was induced by the gap opening of the column-base and beam-column joints. The initial prestress refers to the initial axial load of the PT steel wires for each loading sequence. The changes in initial prestress reflected the condition of prestress loss, which was mainly caused by stress relaxation and the concrete pouring quality defects of stubs.
The prestress increment was gradually increased as the amplitude of the ground motions increased, as shown in Figure 25(a). Under earthquakes of level $7(\mathrm{PGA}=1.56 \mathrm{~g})$, the maximum prestress increment was 8.29, 8.05, and $7.10 \mathrm{kN}$ for the PT steel wires in column (C1), X-direction beams (B14, B24), and $Y$-direction beams (B11, B21), respectively.

The initial prestress of the PT steel wires in the column (C1) fluctuated slightly around the value of $33.04 \mathrm{kN}$ (Figure 25(b)), which was near the design value of $30.78 \mathrm{kN}$. The prestress loss was minimal during the entire loading process. The maximum prestress was gradually increased to $40.30 \mathrm{kN}$ (Figure 25(c)), far less than the measured yield force of PT steel wires $(62.78 \mathrm{kN})$.

The initial prestress of the PT steel wires in $X$-direction beams (B14 and B24) decreased from about $28.19 \mathrm{kN}$ under earthquakes of level 1 to approximately $22.91 \mathrm{kN}$ under earthquakes of level 7 , with the prestress loss of $5.27 \mathrm{kN}$. The initial prestress was close to the design value of $25.01 \mathrm{kN}$. The 


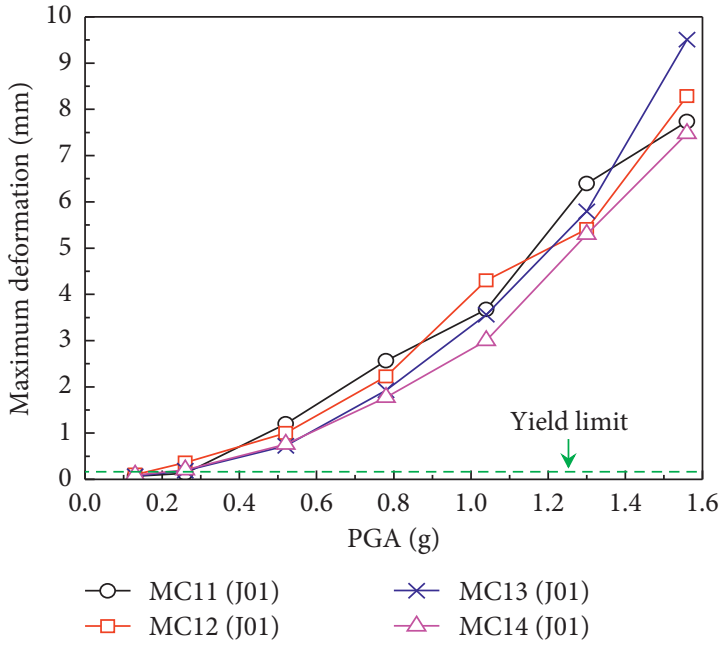

(a)

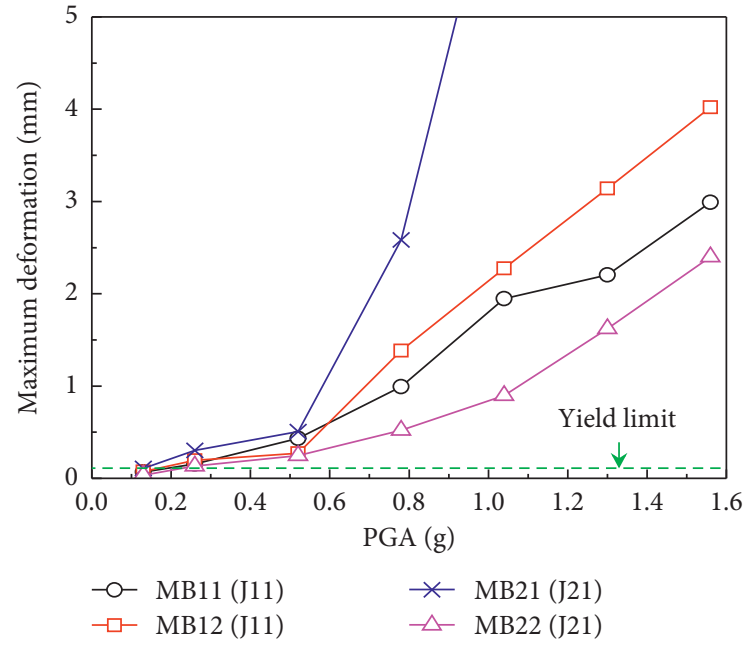

(b)

Figure 26: Maximum deformation of MS dampers. (a) Dampers at column-base joint (J01). (b) Dampers at beam-column joints (J11 and J21).

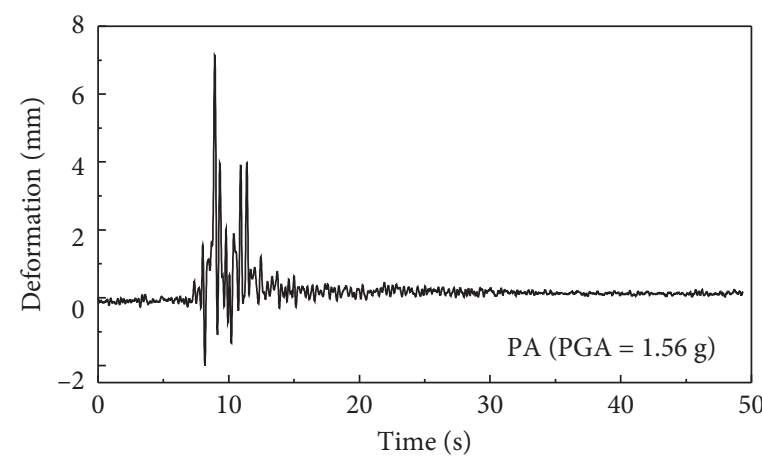

- MC12 (J01)

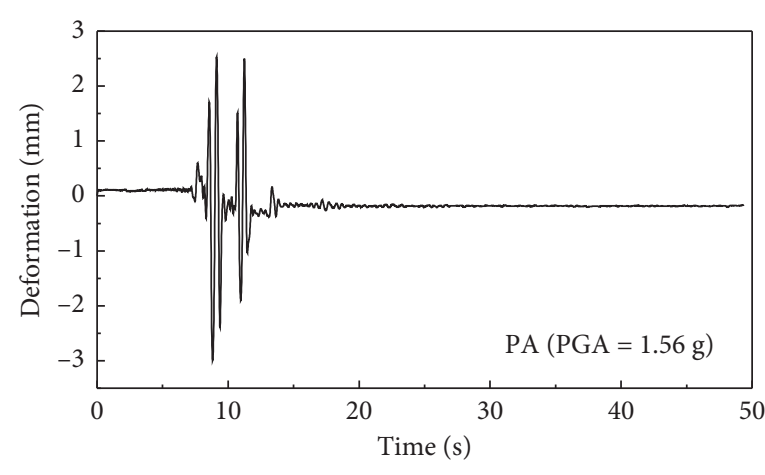

- MB11 (J11)

(a)

(b)

Figure 27: Deformation curves of MS dampers under Parkfield-02_CA earthquakes. (a) Damper MC12 at the column-base joint (J01). (b) Damper MB11 at the beam-column joint (J11).

maximum prestress did not vary a lot during the test process, as shown in Figure 25(c). The maximum prestress was $31.43 \mathrm{kN}$ and far less than the measured yield force $(62.78 \mathrm{kN})$.

The initial prestress of the PT steel wires in beam B21 decreased more rapidly than that in beam $\mathrm{B} 11$. The initial prestress was $32.61 \mathrm{kN}$ (B21) and $35.60 \mathrm{kN}$ (B11) under earthquakes of level 1 , which was near the design value of $32.98 \mathrm{kN}$. The initial prestress was $15.69 \mathrm{kN}$ (B21) and $31.82 \mathrm{kN}$ (B11) under earthquakes of level 7, and the corresponding prestress loss was $16.93 \mathrm{kN}(\mathrm{B} 21)$ and $3.78 \mathrm{kN}$ (B11). The maximum prestress was $33.92 \mathrm{kN}$ (B21) and $37.92 \mathrm{kN}$ (B11), which was less than the measured yield force $(62.78 \mathrm{kN})$.

The above results indicated that the PT steel wires in RC columns and beams remained elastic during the entire loading process; the prestress loss was observed for the PT steel wires in concrete beams of both direction frames because of the stress relaxation and the concrete pouring quality defects of stubs.

3.7. Deformation of MS Dampers. The deformation of MS dampers was measured by the displacement meters installed on each damper, as shown in Figure 4. The criteria of limit states of MS dampers were determined as follows: the yield strain was assumed as $0.114 \%$ for the Q235B round MS bar, which was obtained by dividing the characteristic yield strength of $235 \mathrm{MPa}$ divided by Young's modulus of $2.06 \times 10^{5} \mathrm{MPa}$ [31]. The fracture strain was around $10 \%$ revealed by multiple cyclic tests of dampers [25]. Thus, the damper yield and fracture deformation were obtained by the yield and fracture strain multiplied by the length of the fuse bar, respectively. For the MS dampers at column-base joints (Figure 8), the length of the fuse bar was $150 \mathrm{~mm}$. The yield and fracture deformation were 0.171 and $15 \mathrm{~mm}$. For the 
dampers at beam-column joints (Figure 7), the length of the fuse bar was $100 \mathrm{~mm}$. The yield and fracture deformation were 0.114 and $10 \mathrm{~mm}$.

Figures 26(a) and 26(b) show the maximum deformation of the MS dampers at column-base joint (J01) and beamcolumn joints (J11 and J21), respectively. The deformation of MS dampers increased as the gap opening rotation of the joints increased. The MS dampers did not yield until moderate earthquakes with a PGA of $0.26 \mathrm{~g}$. The maximum deformation was 9.5 and $4.0 \mathrm{~mm}$ for the dampers at columnbase joint (J01) and beam-column joints (J11 and J21), respectively, less than the corresponding fracture deformation. The results indicated that the dampers did not fracture after extreme earthquakes with a PGA of $1.56 \mathrm{~g}$. The deformation of the damper MB21 at the beam-column joint (J21) started to increase extraordinarily under earthquakes of level 4 ( $\mathrm{PGA}=0.78 \mathrm{~g}$ ), due to the bending of damper end, as shown in Figure 12(c).

As examples, Figures 27(a) and 27(b) show the deformation time-history curves of the damper MC12 at the column-base joint (J01) and the damper MB11 at the beamcolumn joint (J11) under the Parkfield-02_CA earthquakes $(\mathrm{PGA}=1.56 \mathrm{~g})$, respectively. It is noteworthy that the dampers installed at column-base joints were mainly in the tension state, whereas the dampers at beam-column joints were in tension and compression states simultaneously.

\section{Conclusions}

Based on shaking table tests performed on a 1/2-scale twostory bidirectional self-centering RC frame structure, the following conclusions could be drawn:

(1) The self-centering RC frames installed in both the $X$ and $Y$ directions showed satisfactory seismic performance and could return to their preearthquake positions with minimal residual deformation even under extreme earthquakes with a PGA of $1.56 \mathrm{~g}$.

(2) The initial natural frequencies were $3.66 \mathrm{~Hz}$ ( $Y$ direction) and $3.82 \mathrm{~Hz}$ ( $X$ direction) and decreased by $27.5 \%$ and $17.1 \%$ under extreme earthquakes with a PGA of $1.56 \mathrm{~g}$. The lateral stiffness of the selfcentering frame installed in the $Y$ direction was smaller than that of the frame installed in the $X$ direction. The lateral stiffness of the self-centering frames installed in both the directions degraded progressively, mainly because of the prestress loss of the PT steel wires and the yielding of the MS dampers.

(3) The displacement responses of the structure in both the directions continually increased as the amplitude of the ground motions increased. The interstory drifts reached $2.47 \%$ and $3.18 \%$ in the $X$ and $Y$ directions, respectively, under extreme earthquakes with a PGA of $1.56 \mathrm{~g}$. Even at this stage, the damage to the main frames was not severe and only microcracks developed on the RC beams and columns. The frames installed in both the directions possessed the self-centering ability to return to their pre-earthquake positions.

(4) The gap opening rotation of the column-base and beamcolumn joints was approximately equal to the interstory drifts. The structural deformation was mainly concentrated at the joints, and hence, the damage to the concrete beams and columns was considerably alleviated. The residual gap rotation of each joint was minimal.

(5) As the gap opening of the joints increased, the prestress increment of the PT steel wires in the concrete beams and columns increased gradually. Prestress loss was observed for the PT steel wires in the beams in both the directions. The PT steel wires remained elastic under all the hazard levels of earthquakes, thereby providing the self-centering ability to the entire structure.

(6) The deformation of the MS dampers increased as the gap opening increased. The MS dampers at the beamcolumn joints experienced rod bending failure during the late loading process, whereas the dampers at the column-base joints dissipated seismic energy more efficiently. The MS dampers did not enter into the yielding phase until moderate earthquakes with a PGA of $0.26 \mathrm{~g}$ and could still work after extreme earthquakes with a PGA of $1.56 \mathrm{~g}$.

Note that this study mainly focuses on investigating the seismic performance of a typical two-story bidirectional selfcentering RC frame building by shaking table tests. To thoroughly investigate the seismic performance of this kind of structure and better verify the effectiveness of the connections designed, future research is needed through nonlinear finite element analyses. For example, a large number of earthquakes can be selected to input into the calibrated finite element model of the test structure. Furthermore, the seismic performance of the bidirectional self-centering RC frames with various structural design parameters (e.g., self-centering ratio, number of bays, and number of stories) can be investigated.

\section{Data Availability}

The data used to support the findings of this study are available from the corresponding author upon request.

\section{Conflicts of Interest}

The authors declare that they have no conflicts of interest.

\section{Acknowledgments}

The authors greatly appreciate the financial support from the National Natural Science Foundation of China (Grant no. 51678543).

\section{References}

[1] S. D. Nakaki, J. F. Stanton, and S. Sritharan, "An overview of the PRESSS five-story precast test building," PCI Journal, vol. 44, no. 2, pp. 26-39, 1999. 
[2] M. J. N. Priestley, S. Sritharan, J. R. Conley, and S. Stefano Pampanin, "Preliminary results and conclusions from the PRESSS five-story precast concrete test building," PCI Journal, vol. 44, no. 6, pp. 42-67, 1999.

[3] G. S. Cheok and H. S. Lew, "Model precast concrete beam-tocolumn connections subject to cyclic loading," PCI Journal, vol. 38, no. 4, pp. 80-92, 1993.

[4] G. S. Cheok and W. C. Stone, "Performance of 1/3-scale model precast concrete beam-column connections subjected to cyclic inelastic loads," Report No. 4 Technical Report, National Institute of Standards and Technology, Gaithersburg, Maryland, USA, 1994.

[5] G. S. Cheok, W. C. Stone, and S. D. Nakaki, "Simplified design procedure for hybrid precast concrete connections," Technical Report, National Institute of Standards and Technology, Gaithersburg, Maryland, USA, 1996.

[6] B. G. Morgen and Y. C. Kurama, "A friction damper for posttensioned precast concrete moment frames," PCI Journal, vol. 49, no. 4, pp. 112-133, 2004.

[7] S. Pampanin, A. Amaris, U. Akguzel, and A. Palermo, "Experimental investigations on high-performance jointed ductile connections for precast frame systems," in Proceedings of the First European Conference on Earthquake Engineering and Seismology, Geneva, Switzerland, 2006.

[8] S. Ozden and O. Ertas, "Behavior of unbonded, post- tensioned, precast concrete connections with different percentages of mild steel reinforcement," PCI Journal, vol. 52, no. 2, pp. 32-44, 2007.

[9] A. Amaris, "Developments of advanced solutions for seismic resisting precast concrete frames," Doctoral Dissertation, University of Canterbury, Christchurch, New Zealand, 2010.

[10] L.-L. Song, T. Guo, and C. Chen, "Experimental and numerical study of a self-centering prestressed concrete moment resisting frame connection with bolted web friction devices," Earthquake Engineering \& Structural Dynamics, vol. 43, no. 4, pp. 529-545, 2014.

[11] M. Nishiyama and F. Watanabe, "Seismic performance of precast column-foundation connection assembled by posttensioning," in Proceedings of the Advanced Materials for Construction of Bridges, Buildings, and Other Structures III, Davos, Switzerland, 2003.

[12] D. Marriott, "The development of high-performance posttensioned rocking systems for the seismic design of structures," Doctoral Dissertation, University of Canterbury, Christchurch, New Zealand, 2009.

[13] D. Marriott, S. Pampanin, and A. Palermo, "Quasi-static and pseudo-dynamic testing of unbonded post-tensioned rocking bridge piers with external replaceable dissipaters," Earthquake Engineering \& Structural Dynamics, vol. 38, no. 3, pp. 331354, 2009.

[14] Z. Cao, H. Wang, and T. Guo, "Fragility analysis of selfcentering prestressed concrete bridge pier with external aluminum dissipators," Advances in Structural Engineering, vol. 20, no. 8, pp. 1210-1222, 2017.

[15] X. Lu, Y. Cui, J. Liu, and W. Gao, "Shaking table test and numerical simulation of a $1 / 2$-scale self-centering reinforced concrete frame," Earthquake Engineering \& Structural Dynamics, vol. 44, no. 12, pp. 1899-1917, 2015.

[16] Y. Cui, X. Lu, and C. Jiang, "Experimental investigation of triaxial self-centering reinforced concrete frame structures through shaking table tests," Engineering Structures, vol. 132, pp. 684-694, 2017.
[17] R. E. Englekirk, "Design-construction of the paramount-a 39story precast prestressed concrete apartment building," $P C I$ Journal, vol. 47, no. 4, pp. 56-71, 2002.

[18] A. Cattanach and S. Pampanin, "21st century precast: the detailing and manufacture of NZ's first multi-storey PRESSSbuilding," in Proceedings of the NZ Concrete Industry Conference, Rotorua, New Zealand, 2008.

[19] S. Pampanin, W. Y. Kam, G. Haverland, and S. Gardiner, "Expectation meets reality: seismic performance of posttensioned precast concrete southern cross endoscopy building during the 22nd Feb 2011 Christchurch earthquake," in Proceedings of the NZ Concrete Industry Conference, Rotorua, New Zealand, 2011.

[20] M. J. N. Priestley, "Direct displacement-based design of precast/prestressed concrete buildings," PCI Journal, vol. 47, no. 6, pp. 66-79, 2002.

[21] M. J. N. Priestley, G. M. Calvi, and M. J. Kowalsky, Displacement-Based Seismic Design of Structures, IUSS Press, Pavia, Italy, 2007.

[22] S. Pampanin, D. Marriott, A. Palermo, and D. Bolognimi, PRESSS Design Handbook, New Zealand Concrete Society (NZCS), Auckland, New Zealand, 2010.

[23] Ministry of Housing and Urban-Rural Development of China, Code for Seismic Design of Buildings (GB 50011-2010), Architecture \& Building Press, Beijing, China, 2010, in Chinese.

[24] X. Lu, G. Fu, W. Shi, and W. Lu, "Shake table model testing and its application," The Structural Design of Tall and Special Buildings, vol. 17, no. 1, pp. 181-201, 2008.

[25] F. Sarti, A. Palermo, and S. Pampanin, "Fuse-type external replaceable dissipaters: experimental program and numerical modeling," Journal of Structural Engineering, vol. 142, no. 12, Article ID 04016134, 2016.

[26] New Zealand Standards (NZS), NZS3101 Appendix B: Special Provisions for the Seismic Design of Ductile Jointed Precast Concrete Structural Systems, New Zealand Standards (NZS), Wellington, New Zealand, 2006.

[27] Pacific Earthquake Engineering Research Center (PEER), NGA-West2: shallow crustal earthquakes in active tectonic regimes, https://ngawest2.berkeley.edu.

[28] H. D. Li, "Site coefficients from NGA-West2 data," Master thesis, Harbin Institute of Technology, Harbin, China, 2015.

[29] FEMA, Quantification of Building Seismic Performance Factors: FEMA P695, Federal Emergency Management Agency, Washington, DC, USA, 2009.

[30] American Society of Civil Engineers (ASCE), Minimum Design Loads for Buildings and Other Structures, American Society of Civil Engineers (ASCE), Reston, Virginia, USA, 2010.

[31] Ministry of Housing and Urban-Rural Development of China, Standard for Design of Steel Structures (GB 50017-2017), Architecture \& Building Press, Beijing, China, 2017, in Chinese. 